\title{
Photoemission through thin dielectric coating films
}

\author{
A.Buzulutskov *, A.Breskin and R.Chechik, \\ Department of Particle Physics \\ The Weizmann Institute of Science, 76100 Rehovot, Israel
}

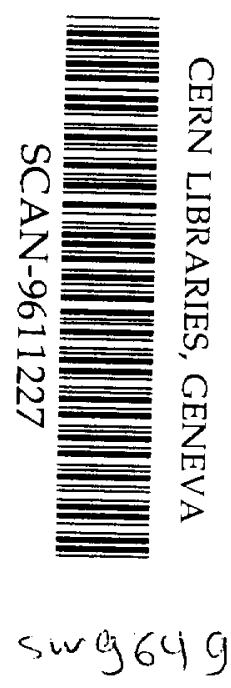

\begin{abstract}
Photoemission through thin coating films was studied in the scope of protection of sensitive photocathodes. The transmission of low energy $(\sim 1 \mathrm{eV})$ electrons was measured for a large number of dielectric films ( $\mathrm{LiF}, \mathrm{NaF}, \mathrm{CsF}, \mathrm{NaI}, \mathrm{MgF}_{2}, \mathrm{BaF}_{2}, \mathrm{SiO}$, $\mathrm{SiO}_{2}, \mathrm{Al}_{2} \mathrm{O}_{3}, n-\mathrm{C}_{36} \mathrm{H}_{74}$ ), evaporated in vacuum on $\mathrm{CsI}$ and $\mathrm{CuI}$ photocathodes. Some films like $\mathrm{CsF}, \mathrm{NaI}$ and $n$ - $\mathrm{C}_{36} \mathrm{H}_{74}$ were found to have a fairly large electron attenuation length, varying from about 20 to $100 \AA$ at a maximum initial electron energy of 1 $\mathrm{eV}$. A thin $\mathrm{CsF}$ layer deposited on top of $\mathrm{CuI}$ and $\mathrm{Al}$ photocathodes was found to significantly increase their quantum yield. An enhancement of the photoyield following exposure to water vapor has been observed for alkali fluoride-coated photocathodes. We interpret this effect as a decrease of the electron affinity by about $0.3-0.4 \mathrm{eV}$, induced by adsorption of polarized $\mathrm{H}_{2} \mathrm{O}$ dipoles.
\end{abstract}

Submitted to the Journal of Applied Physics

\footnotetext{
"Presently at Budker Institute of Nuclear Physics, 630090 Novosibirsk, Russia
} 


\section{Introduction}

Coating photocathodes with thin dielectric films is relevant in the field of photodetection, in particular for detectors combining solid photocathodes with gaseous electron multipliers $[1,2,3]$. Gaseous photomultipliers, currently operating in the ultraviolet (UV) range with CsI convertors [4], have important potential applications in the field of photon imaging, mostly in Ring Imaging Cherenkov (RICH) Detectors .[5] and in the readout of gaseous [1] and solid [2] scintillators. There has been a growing interest in extending the spectral response of gaseous photomultipliers towards the visible range. The few attempts to operate visible photocathodes in gas media $[6,7,8]$ have so far had limited success. We have recently proposed protecting air-sensitive photocathodes with thin solid dielectric films, to permit their short exposure to air and long-term operation in pure gas media [9, 10].

The requirements for coating films are contradictory: on one hand the film should be thin enough to provide good electron transmission; on the other hand it should be sufficiently thick and homogeneous to protect the photocathode against deterioration by chemical reaction with active species such as water, oxygen etc. There are several reasons that influenced our choice of dielectric protective films. It is known that dielectric materials with a large energy gap should have good electron transport properties [11]. Some dielectric films like $\mathrm{LiF}, \mathrm{MgF}_{2}$ and $\mathrm{SiO}$ are being used for protection of Al-based mirrors and optical filters from oxidation $[12,13]$. Also, thin dielectric layers of native oxides, such as $\mathrm{SiO}_{2}$ and $\mathrm{Al}_{2} \mathrm{O}_{3}$, provide sealing from further oxidation of the bulk $[14,15]$.

The initial photoelectron energy relative to the vacuum level, typical for photoemission from visible and UV photocathodes, varies in the range of $0-3 \mathrm{eV}$. There exist considerable experimental data on electron transmission through solids for electron energy above $10 \mathrm{eV}$ (see for example [16] and references therein). However there are only a few theoretical $[17,11,18]$ and experimental $[19,20,21,22,23,24,25,26]$ works on photoemission and electron transport through thin dielectric films, other than $\mathrm{SiO}_{2}$, in the low energy $(\sim 1 \mathrm{eV})$ range. Of particular relevance are refs. $[17,18]$ providing theoretical calculations for alkali halides, and a few experimental works concerning the photoemission through $\mathrm{Al}_{2} \mathrm{O}_{3}$ films [21], $\mathrm{SiO}_{2}$ films (for energies above $8 \mathrm{eV}$ ) [23] and organic films of hexatriacontane [24] and cadmium stearate [25]. Some works deal with electron transport in solid Ar, Kr and Xe films [27. 28, 29].

There is ample literature on low energy electron transport, in $\mathrm{Si} / \mathrm{SiO}_{2}$ systems due to their technological importance (see for example $[30,31,32,33]$ and references therein). Few works in the past considered a field-induced vacuum emission from $\mathrm{Al} / \mathrm{Al}_{2} \mathrm{O}_{3} / \mathrm{Al}$ systems $[34,35]$, containing some information on the electron transport in $\mathrm{Al}_{2} \mathrm{O}_{3}$. To the best of our knowledge there are no experimental data on low energy (a few eV) electron transmission, neither through alkali and alkali-earth halide films nor through oxide films, produced by a racuum evaporation technique. The present work tries to fill this gap.

In the present article we survey the photoelectron transmission properties of a number of films: alkali halides ( $\mathrm{LF}, \mathrm{NaF}, \mathrm{CsF}, \mathrm{NaI}$ ), alkali-earth halides $\left(\mathrm{MgF}_{2}, \mathrm{BaF}_{2}\right)$, oxides ( $\mathrm{SiO}$, $\mathrm{SiO}_{2}, \mathrm{Al}_{2} \mathrm{O}_{3}$ ), and organic films (hexatriacontane). The films were prepared by vacuum eraporation at our laboratory. We measured the quantum yield (QY) spectra of CsI and (uI 
photocathodes coated with these films of different thicknesses, and determined the electron attenuation length for each of them. We found that some of the coating films like CsF, $\mathrm{NaI}$ and $n-\mathrm{C}_{36} \mathrm{H}_{74}$ (hexatriacontane) exhibit rather high electron transmission, and that CsF deposited on $\mathrm{CuI}$ and $\mathrm{Al}$ can even increase their quantum yield.

Effects of exposure to water vapor of coated photocathodes were also studied. During this study we observed an interesting effect of the photoyield enhancement of alkali fluoride-coated photocathodes after their exposure to water vapor [36]. We discuss a possible interpretation of the enhancement as being due to polarized $\mathrm{H}_{2} \mathrm{O}$ dipole adsorption, leading to an effective drop of the electron affinity of the photocathode. We are not aware of any work on the direct measurement of the electron affinity decrease by water adsorption. However, there are some indications that it could happen; for example, it has been observed that the QY of $\mathrm{LiF}, \mathrm{CsBr}$ and $\mathrm{RbI}$ photocathodes in the vacuum ultraviolet region is higher after a short-term contact with ambient air, compared to the QY of the same photocathodes prepared without contact with air [37, 38]. Based on this interpretation and using a simple model of the photoemission from dielectric films, we estimated the drop of the electron affinity induced by water adsorption.

Results reported in this work were obtained with thin films evaporated mostly on CsI and CuI surfaces. These relatively air-stable photocathodes are used only as a testing ground, for the understanding of the experimental procedures and properties of potential coating films. At present, similar experimental procedures are being sucessfully applied by us to visible photocathode coating $[39,40,41]$.

\section{Experimental procedures}

All films investigated were produced by a vacuum evaporation technique. The main experimental setup consists of a high vacuum $\left(1 \times 10^{-7}\right.$ Torr $)$ evaporation chamber, coupled via a $\mathrm{CaF}_{2}$ window to a vacuum monochromator, equipped with a $\mathrm{D}_{2}$ lamp (see Fig.1a). An important feature of the setup is that after preparation of the sample its QY can be measured in situ: the sample is brought from the evaporation site to the measurement position by manipulating the substrate support in vacuum.

The absolute QY of each sample was measured in a reflective mode, in vacuum, as a function of wavelength, in steps of $2-5 \mathrm{~nm}$; a positive voltage is applied to a mesh electrode, placed at a distance of $2 \mathrm{~mm}$ above the photocathode, and the photocurrent induced by a calibrated UV-photon flux is measured on the photocathode. The electric field strength at the photocathode surface was usually maintained at $1.2 \mathrm{kV} / \mathrm{cm}$. A more detailed description of the calibration and measurement procedures can be found elsewhere $[42,43]$. The error in measurement of the QY of a given photocathode sample, defined by fluctuations of the dark current, was about $4 \times 10^{-4}$. The systematic error due to photon flux calibration was about $5 \%$ of the absolute QY value.

A typical procedure for preparation and characterization of the sample under investigation included the evaporation of a $5000 \AA$ thick CSI or $1000 \AA$ thick CuI film on a polished stainless steel substrate (pre-coated with a $500 \AA$ thick $A l$ film in the case of CsI), its con- 
ditioning by heating in vacuum for few hours [44], measurement of the QY, evaporation of the coating film, and re-measurement of the QY. The last two steps were repeated several times, measuring the QY dependence on the film thickness. All the steps are carried out in the same chamber without breaking the vacuum.

The thickness of the film and its deposition rate are monitored with a quartz crystal oscillator [45], with an accuracy of about $0.3 \AA$ and $0.03 \AA / \mathrm{sec}$ respectively. The film thickness was calculated relative to the bulk density of the deposited material, i.e. it was not corrected for the possible reduced packing-density, which in principle could take place $[13,46]$. Most materials were evaporated from Ta or Mo boats, closed with a perforated cover. The evaporation material is typically a powder of high purity [47].

A few words should be said about $\mathrm{SiO}_{2}$ and $\mathrm{Al}_{2} \mathrm{O}_{3}$ films, since their preparation techniques were different. Two techniques were used: a reactive evaporation [48] from a resistive source and an electron beam evaporation. In the reactive evaporation, $\mathrm{SiO}$ or $\mathrm{Al}$ were evaporated from the boat in the presence of oxygen gas, providing fast oxidation of the deposit. The $\mathrm{O}_{2}$ was introduced into the chamber through a needle valve up to a pressure of about $10^{-4}$ Torr. The electron beam evaporation was performed in a different setup, and in this case, the CsI photocathode was exposed to ambient air for a few minutes during transfer. We firmly believe that this transfer did not affect the results, because of the proven stability of CsI [4] and, moreover, of $\mathrm{CsI} / \mathrm{SiO}_{2}$ photocathodes to a short-term exposure to ambient air.

The preparation conditions for the various films are summarized in Table I.

Heating of the substrate in the temperature range of $50-90^{\circ} \mathrm{C}$ was performed in situ in vacuum, with a built-in water heat-exchanger (see Fig.1b). In this case the sample had no contact with air. For heating to higher temperatures, the sample was transferred, through ambient air, to another chamber, heated by a halogen lamp from its rear side, and retransferred to the main vessel for characterization.

An exposure of the sample to water vapor was performed by filling the chamber with distilled water vapor or with humid air, up to a certain pressure (see Fig.1c), and keeping the sample at this pressure for a given time at room temperature $\left(22^{\circ} \mathrm{C}\right)$. Water vapor pressure inside the chamber was carefully monitored with a hygrometer [49], down to $4 \times 10^{-4}$ Torr.

\section{Coating of photocathodes with thin dielectric films}

\subsection{General considerations}

The coating of a photocathode with a thin dielectric film results in the attenuation of photoemission. This can be due to quasielastic and inelastic electron scattering on acoustic and optical phonons within the film (see for example [18]). In addition, a modification of the surface potential barrier can occur, which either enhances or further attenuates the emission yield. Finally, vacuum-deposited dielectrics can contain a large density of electron trapping centers, which can strongly influence the electron transport properties.

In general, the energy band structure notion can be applied to thin dielectric films, similar to that of bulk materials and regardless of their crystalline form, since the essential features of the band structure are determined by the short-range order within the solid [50]. Fig.2 
shows a possible example of the simplified energy-band diagram at the CsI/LiF/vacuum interfaces. Since both the substrate and the coating film are insulators, they are incapable of supplying sufficient charge to the interface to cause significant band bending [50, 51]. The photoemission process is depicted schematically in the figure as well.

The principal photocathodes used in the present study were CsI and CuI. The measurements were performed over a spectral range of $150-250 \mathrm{~nm}(8.3-5 \mathrm{eV})$. Taking into account the photoemission threshold of $6.1 \mathrm{eV}$ and $5.5 \mathrm{eV}$ [44] for CsI and CuI, respectively, the initial energy of the photoelectrons injected into the coating film and measured with respect to the vacuum level ranges between $0-2.2 \mathrm{eV}$ for $\mathrm{CsI}$ and $0-2.8 \mathrm{eV}$ for $\mathrm{CuI}$. These values are valid only under the assumption that the coating film does not affect the relative position of the bottom of the conduction band of the substrate and the vacuum level. Otherwise, one should take into account the modification of the surface barrier induced by the coating film, to estimate the electron energy correctly.

Both CsI and CuI evaporated photocathodes are polycrystalline films. CsI film consists of a mosaic of crystallites of sizes varying typically between 0.3 and $3 \mu \mathrm{m}$; the crystalline structure was confirmed by Atomic Force Microscopy (AFM) and X-ray diffraction studies $[52,53]$. It was reported that CuI films evaporated on different substrates consist of crystallites with a typical dimension of $1 \mu \mathrm{m}$ [54], preferentially oriented with the $\langle 111\rangle$ axis perpendicular to the substrate $[55,56]$.

In the case of an epitaxial growth of a crystalline material on top of a crystalline substrate, the matching of their lattice constants plays a major role. Similarly, a good lattice matching between $\mathrm{CsI}$ or $\mathrm{CuI}$ and the coating material may favour the formation of a layer which replicates the structure of the photocathode underneath. This could also affect the electron transport properties through the coating film. Lattice constants, energy gaps and electron affinities of materials used in the present work are presented in Table II.

Almost all films investigated formed coatings on $\mathrm{CsI}$ and $\mathrm{CuI}$ which were stable in vacuum at room temperature, for at least a few days. The only exception is $n-\mathrm{C}_{36} \mathrm{H}_{74}$, which slightly improved its electron transmission properties after a few hours of storage in vacuum. Some coating films, namely $\mathrm{MgF}_{2}$ and $\mathrm{NaI}$, were found to change their properties after undergoing heat-treatment for a few hours $[9,44]$. In what follows the data are presented for freshly evaporated films, within half an hour after deposition.

For thicknesses above $5-10 \AA$ most of the coating materials studied exibit an exponential decrease of the QY with thickness. The exponential behaviour allows one to define the attenuation length $L$ of the photoyield:

$$
Y(x) \sim \exp (-x / L),
$$

where $Y(x)$ is the QY of a photocathode coated with a film of thickness $x$.

$$
1 / L=1 / L_{\varepsilon}+1 / L_{p h}
$$

where $L_{e}$ and $L_{p h}$ are the electron attenuation and photon absorption lengths of the film. If the coating film does not contribute to the photon adsorption, $L$ is determined by the electron attenuation length: $L=L_{e}$. All thin coating films studied, except NaI, SiO and 
$\mathrm{Al}_{2} \mathrm{O}_{3}$, are very transparent to photons over the spectral range considered in this work. We also ignore the photoemission from the coating film itself, since it is negligible for all the studied materials, except for $\mathrm{NaI}$.

In the following sections the properties of each coating film investigated are given in detail. The following data are presented: QY spectra for a series of coatings, QY versus film thickness for a few selected films and a summary of the thickness-dependence of the QY and the escape length, for all the films.

\subsection{Alkali halide films}

\section{$\mathbf{L i F}$}

Among alkali halides, LiF has the smallest lattice constant. It is used as a protective film for Al mirrors in the extreme ultraviolet $[12,13,57]$.

A surface microanalysis was carried out on a few samples using atomic force microscopy. AFM images of uncoated CsI and CsI coated with about $20 \AA$ thick LiF film are shown in Fig.3. The surfaces were exposed to air prior to and during their analysis. The surface of uncoated CsI shows a polycrystalline texture, inherent in CsI films produced by vacuum evaporation [53]. The CsI surface coated with $\mathrm{LiF}$ is smoother compared to the uncoated one: the CsI grain structure is almost invisible under the thin LiF film. These images indicate that the $\mathrm{LiF}$ film coating is continuous even at very small thickness (few atomic layers). This is not necessarily true for the other materials and other substrates studied.

QY spectra of the CsI photocathode coated with LiF films of different thicknesses are shown in Fig.4. Fig.5 shows the QY as a function of LiF thickness, measured at different wavelengths. For each wavelength the data points fit the exponent. The exact exponential decrease of the QY, including the data points at a "zero" thickness, and the dependence of the attenuation slope on the wavelength (Fig.5) provide an indication that the contribution of photoemission through holes in the film is not dominant even in very thin layers, i.e. that the film is basically continuous.

The monotonic decrease of the QY with thickness also indicates that the LiF coating does not change the position of the vacuum level with respect to the bottom of CsI conduction band. This allows one to determine the maximum initial photoelectron energy in CsI with respect to the vacuum level by subtracting a photoemission threshold of CsI from the incident photon energy.

The electron attenuation length, determined according to eq.(1), is shown in Fig.10; it depends on the photon wavelength and varies from 5 to $10 \AA$ at the maximum initial electron energy of 0.4 and $2.2 \mathrm{eV}$ correspondingly. We are not aware of any available attenuationlength data by other authors.

\section{$\mathrm{NaF}$}

$\mathrm{NaF}$ has a lattice constant which is close to that of CsI (see Table II); the lattice mismatch is only $1 \%$. Therefore one could expect a more regular structure of $\mathrm{NaF}$ on the CsI crystallites, compared to that of LiF on CsI. The electron attenuation length of the $\mathrm{NaF}$ film is by a 
factor of 1.5 larger compared to that of $\mathrm{LiF}$ and varies from 7 to $14 \AA$ over the investigated spectral range (Figs.9,10). In other aspects $\mathrm{NaF}$ coating is very similar to that of $\mathrm{LiF}$.

\section{CsF}

$\mathrm{CsF}$ coating was studied on $\mathrm{CsI}$ and $\mathrm{CuI}$ photocathodes and on an Al surface. Unlike other materials studied, the coating of $\mathrm{CsI}$ and $\mathrm{CuI}$ with thin $(10 \AA)$ film of CsF results in the enhancement of the photoyield (Fig.4). For CsI photocathode the effect is small and takes place at wavelengths longer than $190 \mathrm{~nm}$. For CuI photocathodes the substantial QY enhancement occurs over the whole spectral range. The shift of the red boundary by a value of about $0.4 \mathrm{eV}$ indicates a similar decrease of the surface barrier. Similar to $\mathrm{CuI} / \mathrm{CsF}$, the effect of the $\mathrm{CsF}$ overlayer on $\mathrm{Al}$ was found to be strong, compared to that of $\mathrm{CsI} / \mathrm{CsF}$ (see Fig. 3 in ref. [10]). It is important to note that the CsF-induced enhancement is conserved after a short-term (half an hour) exposure to ambient air.

The observed effect could be connected to the ability of the CsF layer to reduce the work function of the metal or semiconductor substrate, as reported earlier for W [58] and GaAs [59]. The reduction of the work function of $W$ by the CsF adsorption was explained by a dissociation of $\mathrm{CsF}$ molecules [58] resulting in a cesiation of the surface, which is known to be an effective way to reduce the work function of solids.

For CsF films thicker than $10 \AA$ the QY decreases with film thickness. The QY attenuation can be described by an exponential law up to a thickness of about $40-50 \AA$, both for CsI and CuI substrates (Figs.6,9). However for larger thicknesses, in the case of CsF on CsI, the damping rate is appreciably slower than that of an exponent (see Fig.6). This could be explained by the transition from an amorphous or very small microcrystal structure near the $\mathrm{Cs} / \mathrm{CsF}$ interface to a more organized polycrystalline structure at larger film thicknesses, similar to that observed for $\mathrm{LiF}[46]$.

The electron attenuation length determined in the thickness ranges of $9-36 \AA$ and $10-50$ $\AA$ for $\mathrm{CsI} / \mathrm{CsF}$ and for $\mathrm{CuI} / \mathrm{CsF}$ respectively, using expression (1), is presented in Fig. 10 . For $\mathrm{Cs} / \mathrm{CsF}$ it varies from 14 to $30 \AA$ in the respective photon energy range of $6.5-8.3 \mathrm{eV}$.

Attenuation length of $\mathrm{CsF}$ on the $\mathrm{CuI}$ substrate is considerably larger compared to that on CsI, varying from 65 to $170 \AA$ over the respective photon energy range of $5.6-8.3 \mathrm{eV}$. The corresponding range of the maximum initial electron energy is equal to $0.5-3.2 \mathrm{eV}$, assuming a post-coating surface barrier drop equal to $0.4 \mathrm{eV}$ as discussed above. There are no other experimental data on the electron transport in $\mathrm{CsF}$ in this energy range. However, it is interesting that for ideal CsI crystals, theoretical calculations [11] suggest an electron escape length of about $250 \AA$ at an electron energy of $3 \mathrm{eV}$ and $30 \AA$ at $0.5 \mathrm{eV}$, which is not far from our results for $\mathrm{CsF}$.

We suppose that the effect of lattice matching could be the cause for the difference in attenuation lengths of $\mathrm{CsF}$ on $\mathrm{CsI}$ and $\mathrm{CuI}$ substrates. Indeed, $\mathrm{CsF}$ has a lattice constant which is very close to that of CuI (see Table II): the mismatch is of only $0.3 \%$, while the mismatch between $\mathrm{CsF}$ and $\mathrm{CsI}$ is large, of $32 \%$. Notice, that a lattice matching between the substrate and the coating film is usually considered as a major condition for an epitaxial growth of a perfect crystalline structure. Thus one could expect better electron transmission 
of CsF on CuI, compared to CsF on CsI.

\section{$\mathrm{NaI}$}

We found $\mathrm{NaI}$ to be one of the most transmissive materials for low energy electrons. NaI coating was studied on both $\mathrm{CsI}$ and $\mathrm{CuI}$ photocathodes. In contrast to other coating materials, the contribution of photon absorption in $\mathrm{NaI}$ to the photoyield attenuation, below $240 \mathrm{~nm}$, can be substantial. The absolute light absorption coefficient of NaI films was measured in refs. $[60,61]$ : the absorption length varies from 1000 to $300 \AA$ at photon energies $5.2-6.7 \mathrm{eV}$.

CsI/NaI films show a decrease rate of the QY with a thickness which is slower-thanexponential (Fig.4). The reason is that apart from the light absorption, NaI contributes electrons from its own photoemission, at wavelengths shorter than $180 \mathrm{~nm}$ [44]. This contribution was taken into account and subtracted, while estimating the electron attenuation length using formula (1). For that purpose it was independently evaluated by measuring the QY spectra of $\mathrm{NaI}$ films freshly deposited on a stainless steel substrate. These spectra are shown in Fig.4 as dot-dashed lines in $\mathrm{CsI} / \mathrm{NaI}$ and $\mathrm{CuI} / \mathrm{NaI}$ plots. We did not observe substantial differences in the QY for NaI thicknesses varying from 100 to $500 \AA$. Comparing the QY spectra of a $100 \AA$ thick NaI film on a stainless steel substrate and $250 \AA$ thick layer of $\mathrm{NaI}$ on CsI (Fig.4, CsI/NaI plot), one can see that for the latter the photoemission of the $\mathrm{NaI}$ itself dominates.

QY-thickness dependences for CsI/NaI films, after substraction of the photoemission contribution of $\mathrm{NaI}$, are shown in Fig.7 and are well described by an exponential attenuation. It becomes clear from the figure that a very thin NaI layer slightly increases the surface barrier. The effective attenuation length determined for NaI thickness larger than $10 \AA$, is shown in Fig.10; it varies from 14 to $70 \AA$ in the photon energy range $6.5-8.3 \mathrm{eV}$. The attenuation length is smaller than the photon absorption length, approximately by a factor of 4 . Therefore, in a first approximation, with an accuracy of $25 \%$, the total attenuation length measured can be identified as the electron attenuation length. We may conclude that among all coating films on CsI investigated in this work, NaI has the highest electron transmission.

$\mathrm{NaI}$ coating on CuI gives mysterious results: even for very thick NaI film, of $1000 \AA$, the QY of $\mathrm{CuI} / \mathrm{NaI}$ is significantly larger than the QY of $\mathrm{NaI}$ itself, as seen in Fig.4 (CuI/NaI plot). Also, the attenuation length, obtained by applying a similar procedure to that applied $10 \mathrm{CsI} / \mathrm{NaI}$, is surprisingly large, being in complete contradiction with the data on light absorption in $\mathrm{NaI}$ [60]. For example, at photon encrgies of $6.7 \mathrm{eV}$ the attenuation length of $\mathrm{NaI}$ on $\mathrm{CuI}$ is $420 \AA$. i.e. larger than the light absorption length of $\mathrm{NaI}$ (equal to $300 \AA$ ), which violates expression (2).

A possible explanation of these results could be an ion diffusion between $\mathrm{CuI}$ and $\mathrm{NaI}$ lavers: $\mathrm{CuI}$ is known to be a superionic conductor with extremely high mobility of $\mathrm{Cu}^{+}$ ions [62], and both $\mathrm{CuI}$ and $\mathrm{NaI}$ have the same type of anion. This could lead to an easy cation exchange between $\mathrm{CuI}$ and NaI films. Consequently, the $\mathrm{CuI}$ content in the topmost layers could be enriched, acting as a source of the observed photoemission. This possible 
mechanism should be confirmed by further X-ray spectroscopy (XPS) and X-ray difraction studies.

\subsection{Alkali earth halide films}

\section{$\mathrm{MgF}_{2}$}

$\mathrm{MgF}_{2}$ is the most widely used optical coating material. Protective $\mathrm{MgF}_{2}$ films of thickness of $250 \AA$ provide long-term stability to Al mirrors in air [57].

In very thin layers the $\mathrm{MgF}_{2}$ coating provides an example of a discontinuous film : the QY of CsI after coating with $5 \AA$ thick layer is practically unchanged, almost independently of the wavelength (Figs.4,9). This should be the case when the photoemission occurs through holes in the coating film, as discussed before. The discontinuity of thin $\mathrm{MgF}_{2}$ films can be related to its lower lattice symmetry: it has a tetragonal structure, while all alkali halides have a cubic structure.

For thicknesses larger than $5 \AA$ the QY drop obeys an exponential law, indicating film continuity, and allowing for the determination of the electron attenuation length, shown in Fig.10. The latter is one of the smallest among the materials investigated in this work and it decreases with wavelength faster than for the other fluorides.

It is known $[13,46]$ that $\mathrm{MgF}_{2}$ tends to form films with low packing density, of about 0.7 , if deposited on a substrate at room temperature. The packing density could be increased by evaporation at elevated substrate temperatures, of about $300^{\circ} \mathrm{C}$, or by annealing the film after deposition [13]. We proceeded with a post-evaporation heat treatment in vacuum at $60^{\circ} \mathrm{C}$, and found that the QY was indeed considerably enhanced. It should be remarked that of all coating materials investigated here, $\mathrm{MgF}_{2}$ and $\mathrm{NaI}$ turned out to be the only ones which significantly changed their properties under heating.

\section{$\mathrm{BaF}_{2}$}

Not much can be said about $\mathrm{BaF}_{2}$, since it turned out that the QY spectra of $\mathrm{CsI} / \mathrm{BaF}_{2}$ were not easily reproducible from sample to sample. We can only state that the electron transmission properties of $\mathrm{BaF}_{2}$ films are situated between those of $\mathrm{MgF}_{2}$ and $\mathrm{NaF}$.

\subsection{Oxide films}

Oxides can be very effective protective films, even in extremely thin layers, if well prepared. Indeed, native layers of $15-20 \AA$ thick $\mathrm{SiO}_{2}$ and of $35 \AA$ thick $\mathrm{Al}_{2} \mathrm{O}_{3}$ provide efficient sealing from further oxidation of $\mathrm{Si}$ and $\mathrm{Al}[14,15,21]$. Evaporated $\mathrm{SiO}, \mathrm{SiO}_{2}$ and $\mathrm{Al}_{2} \mathrm{O}_{3}$ films are amorphous.

\section{$\mathrm{SiO}$}

$\mathrm{SiO}$ films are widely used for optical [13] and dielectric [63] applications. Since the photon absorption length of the $\mathrm{SiO}$ film, in the UV region, is above $250 \AA$ [64], i.e. much larger 
than the thicknesses used in our study, the photoyield attenuation can be fully attributed to the electron attenuation. Thus, the electron attenuation length of $\mathrm{SiO}$ is situated between that of $\mathrm{MgF}_{2}$ and $\mathrm{LiF}$, varying from 3 to $9 \AA$ (Fig.10).

\section{$\mathrm{SiO}_{2}$}

We prepared $\mathrm{SiO}_{2}$ films using both a reactive evaporation of $\mathrm{SiO}$ and an electron beam evaporation of quartz. For some of the $\mathrm{CsI} / \mathrm{SiO}_{2}$ samples prepared with the $\mathrm{SiO}_{2}$ film produced by reactive evaporation, we proceeded with an $\mathrm{X}$-ray photoelectron spectroscopy (XPS) of the surface. Distinct XPS-signals of $\mathrm{Cs}, \mathrm{I}, \mathrm{Si}$ and O were detected, confirming that $\mathrm{SiO}$ was indeed deposited on top of CsI. The shape and the position of the Si peak corresponds to $85 \%$ of $\mathrm{Si}$ bound as $\mathrm{SiO}_{2}$, and approximately $15 \%$ bound as $\mathrm{Si}_{2} \mathrm{O}_{3}$. This confirms that most of $\mathrm{SiO}$ was transformed into $\mathrm{SiO}_{2}$ during the reactive evaporation. The estimation of the $\mathrm{SiO}_{2}$ layer thickness, derived from the relative intensity of signals for Cs, $\mathrm{I}$ and $\mathrm{Si}$ species, was in agreement with the quartz oscillator data.

Fig.9 shows the QY as a function of the $\mathrm{SiO}_{2}$ thickness, obtained with different CsI samples. Both preparation techniques give rise to similar results: electron damping with thickness can be described by an exponent.

The electron attenuation length of $\mathrm{SiO}_{2}$ (Fig.10) is close to that of $\mathrm{MgF}_{2}$ : at the maximum initial photoelectron energy of about $2.2 \mathrm{eV}$, it is equal to $8 \AA$. This value is fairly consistent with the attenuation length of $\mathrm{a} \mathrm{SiO}_{2}$ film thermally grown on $\mathrm{Si}$ and measured in a photoemission experiment [23] for photoelectron energy of $8 \mathrm{eV}$. This is, however, somewhat smaller than the electron energy relaxation length in $\mathrm{SiO}_{2}$, of $30 \AA$, reported in ref. [30] obtained in a field emission experiment.

\section{$\mathrm{Al}_{2} \mathrm{O}_{3}$}

$\mathrm{Nl}_{2} \mathrm{O}_{3}$ films were prepared by reactive evaporation of $\mathrm{Al}$ and by an electron beam evaporation of sapphire. Both preparation techniques gave rise to consistent results.

$\mathrm{Al}_{2} \mathrm{O}_{3}$ coating on $\mathrm{CsI}$ provides a good example for increase of the surface barrier (Fig.9): the QY of CsI drops considerably after coating with $7 \AA$ thick $\mathrm{Al}_{2} \mathrm{O}_{3}$ layer. For larger thicknesses the QY decrease is moderate and can be described by an exponent. The attenuation length of $\mathrm{Al}_{2} \mathrm{O}_{3}$ determined for this exponential fit has an intermediate value, between that of $\mathrm{LiF}$ and $\mathrm{NaF}$ (Fig.10): at a photon energy of $8.3 \mathrm{eV}$ it amounts to $10 \AA$. The photon absorption length of the $\mathrm{Al}_{2} \mathrm{O}_{3}$ film varies between 250 and $1000 \AA$ in the relevant wavelength range [21], therefore the photoyield attenuation can be attributed to the electrons.

Since the $\mathrm{Al}_{2} \mathrm{O}_{3}$ layer significantly modifies the surface barrier, the initial electron energy with respect to the racuum level is also changed, as compared to the uncoated CsI film. The change is estimated from the red boundary shift, to be of the order of $0.7 \mathrm{eV}$. Therefore the maximum initial electron energy corresponding to the photon energy of $8.3 \mathrm{eV}$ is about 1.5 eV.

The extracted electron attenuation length can be compared to the value of $130 \AA$, measured by photoemission from $\mathrm{Al}$ through $\mathrm{Al}_{2} \mathrm{O}_{3}$ films grown by anodization, for a maximum initial photoelectron energy of $7.8 \mathrm{eV}[21]$. The large discrepancy could result from the large 
difference in electron energy and the different film preparation techniques. On the other hand we can use the data of energy loss for hot electrons in $\mathrm{Al}_{2} \mathrm{O}_{3}[34,35]$, measured in $\mathrm{Al} / \mathrm{Al}_{2} \mathrm{O}_{3} / \mathrm{Al}$ tunnel structures. It gives an electron energy-relaxation length of the order of $10-30 \AA$ at an energy of $1 \mathrm{eV}$, which is consistent with our data.

\subsection{Organic films}

$n-\mathrm{C}_{36} \mathrm{H}_{74}$

n- $\mathrm{C}_{36} \mathrm{H}_{74}$ (hexatriacontane, HTC) is the only organic coating film studied in the present work. This long-chain paraffin insulator was reported [65] to have a negative electron affinity (NEA) and to be a model substance for polyethylene. Its important advantages are the possibility of preparation by vacuum evaporation and the stability in ultra-high vacuum and in ambient air conditions [24].

Fig.8 shows the QY as a function of the HTC film thickness at different wavelengths, measured for two different CsI samples. HTC has a relatively large electron attenuation length, of $40 \AA$ at the maximum electron energy of $2.2 \mathrm{eV}$, slowly decreasing to $35 \AA$ at 0.8 $\mathrm{eV}$ (see Fig.10). It should be noted that our results are in good quantitive agreement with the results obtained in another photoemission experiment [24], where the electron attenuation length of HTC varied from $45 \AA$ at the electron energy of $2.2 \mathrm{eV}$ to $30 \AA$ at $1 \mathrm{eV}$.

\section{Effects of exposure to water vapor}

\subsection{Experimental results}

Fig.11a shows the evolution of the QY of a CsI photocathode coated with a $22 \AA$ thick LiF film, following an exposure to humid air, re-exposure to vacuum, heating and further long exposure to air. One call see a dramatic enhancement of the photoemission after an exposure to humid air inside the cliamber; the difference in the QY can reach a factor of 20 at $190 \mathrm{~nm}$. The stability of the effect should be emphasized: once the sample has been subjected to a $\mathrm{H}_{2} \mathrm{O}$ vapor "treatment", its enhanced photoemission is rather stable when further exposed to vacuum (even at elevated temperatures) and to ambient air, for a few days. However, long-term ( 1 month) exposure to ambient air destroys the photoemission enhancement.

We verified that the effect is due to LiF and not to CsI, by treating an uncoated CsI surface in a similar way. No enhancement has been found; after the treatment the QY either remained unchanged or decreased, depending on the degree of humidity and the exposure time.

It has also been proved that the observed $Q Y$ enhancement is due to $\mathrm{H}_{2} \mathrm{O}$ vapor and not to other impurities in air, by exposing a $\mathrm{Cs} / \mathrm{LiF}$ sample to a controlled amount of $\mathrm{H}_{2} \mathrm{O}$ vapor in the vacuum chamber (see Fig.11b). In this experiment the exposure varied from 2 minutes at 0.3 Torr $\mathrm{H}_{2} \mathrm{O}$ to 2 hours at 7 Torr $\mathrm{H}_{2} \mathrm{O}$. Further exposure to $\mathrm{H}_{2} \mathrm{O}$ vapor did not increase the photoyield, indicating a saturation of the enhancement. A major increment of the photoyield takes place after an exposure to 7 Torr $\mathrm{H}_{2} \mathrm{O}$, which could indicate the 
necessity for a certain density of $\mathrm{H}_{2} \mathrm{O}$ molecules to initiate the effect. Comparing Figs. 11a and $11 \mathrm{~b}$ we conclude that the magnitude of the water-exposure effect is the same in humid air and in pure $\mathrm{H}_{2} \mathrm{O}$ vapors, i.e. the presence of air does not noticeably affect the process.

The magnitude of the enhancement decreases with a decrease of the film thickness. This is seen in Fig. 12 showing the results for a $10 \AA$ thick LiF film. Nevertheless, for thinner films the QY after exposure to $\mathrm{H}_{2} \mathrm{O}$ vapor can even exceed that of uncoated CsI for wavelengths above 190-200 nm (see Figs.12,14a).

Very similar results were obtained for CsI photocathodes coated with $\mathrm{NaF}$ and CsF films and $\mathrm{CuI}$ photocathodes coated with CsF films. In particular, the final magnitude of the photoyield enhancement was found to be roughly the same for the three alkali fluorides, if they have the same initial QY values. However, the saturation was found to be faster compared to LiF. This is seen in Fig.13 showing the dependence of the QY of CsI/LiF, $\mathrm{CsI} / \mathrm{NaF}$ and $\mathrm{CsI} / \mathrm{CsF}$ photocathodes on the water "dosage" expressed in Langmuirs (L) ( $1 \mathrm{~L}=10^{-6}$ Torr $\cdot \mathrm{sec}$ ). Due to our simplified experimental arrangement we could provide a controlled water dosage above $10^{5} \mathrm{~L}$. But as one can see, the photoyield signal does not change at this dosage; the signal starts increasing only at $10^{7} \mathrm{~L}$ and saturates at about $10^{8} \mathrm{~L}$ for $\mathrm{CsF}, 10^{9} \mathrm{~L}$ for $\mathrm{NaF}$ and $10^{10} \mathrm{~L}$ for LiF. Note that the saturation dosages appear to follow a descending order from $\mathrm{LiF}$ to $\mathrm{CsF}$, in correlation to the increase of their water solubility.

It is also interesting to note that the effect slightly enhances from $\mathrm{LiF}$ to $\mathrm{NaF}$ and then to $\mathrm{CsF}$, in accordance with their increasing solubility in water (Fig.14a). These three alkali fluorides are known to be hygroscopic. For comparison non-hygroscopic alkali-earth fluoride films like $\mathrm{MgF}_{2}$ and $\mathrm{BaF}_{2}$ on CsI were studied (Fig.14b). The water adsorption effect for them was found to be negligible, which supports the assumption for the enhancement being related to $\mathrm{H}_{2} \mathrm{O}$.

We studied the effect of exposure to $\mathrm{H}_{2} \mathrm{O}$ vapor for other photocathodes like $\mathrm{NaI}, \mathrm{CsI} / \mathrm{SiO}_{2}$ . $\mathrm{CsI} / \mathrm{Al}_{2} \mathrm{O}_{3}, \mathrm{CsI} / \mathrm{NaI}$ and $\mathrm{CuI} / \mathrm{NaI}$. A little enhancement of the photoyield was observed for $\mathrm{CsI} / \mathrm{SiO}_{2}$ and it took several days to reach a photoyield saturation. The other photocathodes had no distinct response to short-term contact with $\mathrm{H}_{2} \mathrm{O}$.

\subsection{Polarized water adsorption}

We propose to interpret the photoemission enhancement results in terms of modification of the electron affinity. induced by surface adsorption of polarized $\mathrm{H}_{2} \mathrm{O}$ molecules. Indeed, it is well known that the electron affinity of solids can be reduced by a surface adsorption of molecules with either a low ionization potential, for example Cs $[70,71]$, or a high polarizability, such as noble gases [72]. Qualitatively, the effect of the electron affinity reduction is explained by attraction of the electrons of the adsorbed molecules towards the solid. This leads to a formation of a double-charged layer. providing a drop of the surface potential barrier.

In principle there should exist another way to create such a double layer structure, namely by a polarized adsorption of molecules with a high dipole moment. A surface potential step induced by an adsorbed layer of oriented dipoles is equal to

$$
\Delta U=4 \pi n \mu_{\perp} \quad \text {. }
$$


where $n$ is the number of adsorbed molecules per unit area, $\mu_{\perp}$ is the average component of the molecular dipole moment in the direction perpendicular to the surface plane. If $\mu_{\perp}$ is antiparallel to the surface normal, the surface barrier is reduced resulting in the enhancement of the photoyield. The water molecule is one of the best candidates for this task, because of its particularly high dipole moment of $1.84 \mathrm{D}\left(1\right.$ Debye $\left.=10^{-18} \mathrm{esu}\right)$. Orientation effects in water adsorption should be particularly strong on ionic salts like those of halides, due to their highly polar structure.

However, little is known about water adsorption on alkali halides ( $\mathrm{LiF}, \mathrm{NaF}, \mathrm{NaCl}$ ) $[73,74,75]$ and alkali-earth halides $\left(\mathrm{BaF}_{2}, \mathrm{CaF}_{2}\right)$ [76] and even less about $\mathrm{H}_{2} \mathrm{O}$ molecule orientation on their surfaces. The latter has been recently studied in refs. [76, 77, 78] with an optical second-harmonic generation (SHG) technique. The following interpretation of their results $[76,78]$ is particularly relevant to our work:

- Water adsorbs on $\mathrm{NaCl}(100)$ and $\mathrm{BaF}_{2}$ (111) both in air and in vacuum, even at room temperature. This is in contrast to previous expectations [74], where only cooling of crystals much below $0{ }^{\circ} \mathrm{C}$ could induce water adsorption, and in accordance with our observations for $\mathrm{LiF}, \mathrm{NaF}$ and $\mathrm{CsF}$.

- Water adsorption on $\mathrm{NaCl}(100)$ is predicted to have a polarized nature. At small water coverage, below 0.5 monolayer, the dipole moment of $\mathrm{H}_{2} \mathrm{O}$ molecules is expected to be oriented antiparallel to the surface normal. This dipole orientation should strongly reduce the work function of the electrons.

- It is predicted that beyond one monolayer coverage a $2 \mathrm{D}$-ice bilayer is formed on $\mathrm{NaCl}(100)$ surface at room temperature, still having a non-vanishing perpendicular component of the $\mathrm{H}_{2} \mathrm{O}$ dipole moment, of the order of $0.4 \mathrm{D}$ (Fig.4 in ref.[78].) This concept implies that the highly polar character of alkali halides stabilizes 2D-ice layers on their surfaces, even at room temperature.

Substituting the value of $0.4 \mathrm{D}$ into (3) and taking into account the $\mathrm{H}_{2} \mathrm{O}$ molecule concentration within one 2D-ice layer (17.5 $\AA^{2}$ area per $\mathrm{H}_{2} \mathrm{O}$ molecule) [79], we can roughly predict a work function drop at the alkali-halide/ice interface to be about $0.9 \mathrm{eV}$. This should be compared to our estimations of the electron affinity decrease of $0.4 \mathrm{eV}$ obtained from experimental data for $\mathrm{LiF}$ and $\mathrm{NaF}$, as discussed in the next section.

We suggest that quasistable conditions might exist, at which a certain $\mathrm{H}_{2} \mathrm{O}$ dipole orientation, namely towards the film, could considerably reduce the electron affinity of alkali halides.

\subsection{Estimation of the electron affinity decrease}

Motivated by these arguments, we tried to estimate the value of the electron affinity decrease for $\mathrm{CsI} / \mathrm{LiF}$ and $\mathrm{CsI} / \mathrm{NaF}$ films using a simplified three-step model [80] of the photoemission from dielectric films, similar to that used in $[81,66]$. Fig.2 shows a possible energy diagram at the $\mathrm{CsI} / \mathrm{LiF} /$ vacuum interface. Note that the difference between the vacuum level and the bottom of the CsI conduction band, $E_{a}(\mathrm{CsI})$, does not change after coating with LiF; 
this assumption, supported by photoelectron transmission data presented in section 3.2 , is also valid for the $\mathrm{CsI} / \mathrm{NaF}$ system. This is however not the case for $\mathrm{CsF}$ coatings: thin $\mathrm{CsF}$ overlayer reduces the surface barrier of $\mathrm{CsI}$ and especially of $\mathrm{CuI}$. Since the exact value of this reduction is generally unknown, we excluded $\mathrm{CsF}$ from the following calculations.

A photoemission process consists of three steps [80]: photoexcitation of an electron from the valence band to the conduction band of CsI, a transport through the CsI and LiF films to the surface, and an escape to vacuum. The main simplification of the model is the assumption that electrons in the conduction band of both CsI and LiF are distributed isotropically in angle and uniformly in energy. This assumption has been successfully applied to explain a threshold behaviour of the photoemission from metals (Fowler dependence) [81] and to describe a field-enhancement effect in the photoemission from CsI [66]. In deriving the expression for the QY we followed these references; the deriviation is presented in the Appendix.

The QY of the photoemission from $\mathrm{CsI} / \mathrm{LiF}$ films is given by

$$
Y=\frac{f}{2 \Delta E}\left[g^{1 / 2} E_{m}^{1 / 2}-E_{0}^{1 / 2}\right]^{2}
$$

Here $E_{m}$ and $\Delta E$ are respectively the initial maximum energy and the initial energy spread of photoelectrons in the CsI conduction band. $E_{0}$ is the surface potential barrier at the $\mathrm{LiF} /$ vacuum interface; measured from the bottom of the LiF conduction band, it is equal to the $\mathrm{LiF}$ electron affinity $E_{a} . f$ and $g$ are the normalization and electron transport parameters depending on the LiF thickness.

First, the experimental QY spectra before contact with $\mathrm{H}_{2} \mathrm{O}$, for a certain $\mathrm{LiF}$ thickness, are used to fit the parameters $f$ and $g$. During this fit an arbitrary fixed value is assigned to $E_{0}$ (in particular we used $E_{a}=1 \mathrm{eV}$ which is close to that quoted in the literature [71]). Supposing that the electron transport properties in LiF remain unchanged after contact with $\mathrm{H}_{2} \mathrm{O}$ and that the only effect of $\mathrm{H}_{2} \mathrm{O}$ is the modification of the surface barrier, we then fit the spectra measured after exposure to $\mathrm{H}_{2} \mathrm{O}$ with fixed values of $f$ and $g$ obtained before exposure and with $E_{0}$ being a single free parameter. The difference between the initial value and that of the fitted one provides us with the clesired value of the electron affinity variation $\Delta E_{a}$. The wavelength range for the fits was $160-190 \mathrm{~nm}$ and $160-200 \mathrm{~nm}$ for the data before and after exposure to $\mathrm{H}_{2} \mathrm{O}$ correspondingly. A similar procedure was applied to NaF-coated films.

An example of the model fit to experimental data is shown as solid lines in Fig.12. For uncoated CsI the model successfully describes the shape of the QY spectrum below 200 $\mathrm{Im}$, the wavelength correspending to the sum of the energy gap and electron affinity of ('sl. However, at longer wavelengths the model has limitations due to other mechanisms, for example the decay of excitons on F-centers [60, 19], which are not taken into account.

The model describes reasonably well the increment in quantum yield between the data. obtained before and after contact with $\mathrm{H}_{2} \mathrm{O}$, in the range 160-190 nm. Estimations of $\Delta E_{a}$ are presented in Table III. The values for $\mathrm{LiF}$ and $\mathrm{NaF}$ are very similar; they are smaller for thinner films, $0.15-0.17 \mathrm{eV}$, while above $10 \mathrm{~A}$ they tend to be constant, of the order of 0.3-0.4 eV. According to (3) this is by a factor of 10-20 less compared to a hypothetical limit, 
which might be reached if all $\mathrm{H}_{2} \mathrm{O}$ molecules would form a layer with their dipole moment directed antiparallel to the surface normal.

\section{$5 \quad$ Summary and conclusions}

The aim of this research is the study of physical properties of thin dielectric film coatings, for possible protection of sensitive photoemissive materials, i.e. visible photocathodes. In this work we presented the results of a systematic study of photocathode coating with various thin films: alkali halides, alkali-earth halides, oxides and organics. All films were prepared and studied in the same way, applying vacuum deposition techniques and measuring the attenuation of the quantum yield (QY) spectra of coated photocathodes at different film thicknesses. For reasons of simplicity, we deposited the films on relatively air-stable photocathodes, namely CsI and CuI.

Though the QY data provide only an integral information on the photoemission (for example, only the maximum photoelectron energy can be evaluated), these measurements directly estimate the QY attenuation due to coating, which is of prime interest for practical applications. We have extracted the electron attenuation length from the QY-thickness dependences; for some of the films ( $\mathrm{LiF}, \mathrm{NaF}, \mathrm{CsF}, \mathrm{NaI}, \mathrm{MgF}_{2}$ ) the attenuation length (in the $1 \mathrm{eV}$ energy range) was determined for the first time.

The observed QY dependence on the thickness of various coating films can be summarized as follows (see Fig.9). One should distinguish the effects measured at film thicknesses of the order of 1-2 monolayers, i.e. below $10 \AA$, from that observed above $10 \AA$. For some films, like $\mathrm{LiF}, \mathrm{NaF}, \mathrm{SiO}, \mathrm{SiO}_{2}$ and $n-\mathrm{C}_{36} \mathrm{H}_{74}$, the QY decreases, below $10 \AA$, by the same law as that observed for larger thicknesses. This could be interpreted as possible evidence for continuity of the film and for non-modification of the surface barrier after coating. For other films, whose thickness dependence in very thin layers differs from that of thicker ones, three types of behavior are observed: 1) the QY stays practically constant independently of the wavelength $\left(\mathrm{MgF}_{2}\right)$, obviously indicating the discontinuity of the film; 2$)$ the QY increases $(\mathrm{CsF})$, indicating the decrease of the surface barrier; 3$)$ the QY abruptly drops $\left(\mathrm{Al}_{2} \mathrm{O}_{3}\right.$ and $\mathrm{NaI}$ ), indicating the increase of the surface barrier.

An important experimental result is the chemical stability of most of the dielectric coatings on $\mathrm{CsI}$ and $\mathrm{CuI}$ photocathodes. Another observation is that $\mathrm{CsF}, \mathrm{NaI}$ and $n-\mathrm{C}_{36} \mathrm{H}_{74}$ have fairly large electron attenuation length, varying, on CsI substrates, from 20 to $50 \AA$ at a maximum initial electron energy of $1 \mathrm{eV}$. Moreover, the electron attenuation length of $\mathrm{CsF}$ on CuI was found to be considerably larger than that on CsI. The possible interpretation could be an epitaxial growth of $\mathrm{CsF}$ on $\mathrm{CuI}$ due to the matching of their lattice constants. Thus, $\mathrm{CsF}, \mathrm{NaI}$ and $n-\mathrm{C}_{36} \mathrm{H}_{74}$ films can be good candidates for protective coatings of sensitive photocathodes.

Intriguing results were obtained with ultrathin CsF coating: a 1-2 monolayer thick CsF film considerably increases the QY of $\mathrm{CuI}$ and $\mathrm{Al}$ photocathodes, shifting the red boundary, in the case of $\mathrm{CuI}$, by about $0.4 \mathrm{eV}$. The possible explanation is a dissociation of $\mathrm{CsF}$ molecules on metal or semiconductor substrates resulting in a partial cesiation of the surface 
[58]. The fact that the increase in QY was found to be stable in air for tens of minutes is not very surprising, if we take into account relative stability of cesiated diamond film surfaces, reported recently [82].

Exposure of alkali-fluoride-coated photocathodes to water vapor gives rise to an interesting effect of QY enhancement. We explain this effect by a possible reduction of the electron affinity of the coating film, induced by adsorption of polarized $\mathrm{H}_{2} \mathrm{O}$ molecules. We estimated the order of magnitude of this reduction to be of $0.3-0.4 \mathrm{eV}$, using a simplified model of photoemission. More precise estimates of the effect will be obtained after the elaboration of more rigorous model including microscopic approach. Of particular interest are the study of the temperature dependence of the effect and the possible use of other liquid or gaseous adsorbants with high molecular dipole moment. If successfull, these investigations will result in the production of new, highly efficient, negative-electron-affinity photocathodes.

An example of the ultimate application of the results obtained in the present work is the coating of visible $\mathrm{Cs}_{3} \mathrm{Sb}$ photocathodes with thin dielectric protective films [39, 41]. It was confirmed that few coating films, namely $\mathrm{NaI}, \mathrm{CsF}$ and $n-\mathrm{C}_{36} \mathrm{H}_{74}$, preserve their good electron transmission properties on $\mathrm{Cs}_{3} \mathrm{Sb}$ photocathodes. Moreover, it was found that $\mathrm{NaI}$ films provide protection of $\mathrm{Cs}_{3} \mathrm{Sb}$ photocathodes against exposure to a considerable amount (tens of Torr) of oxygen, which could permit handling in dry air or operation in gas media. This may open new ways in the development of large-area imaging detectors for visible photons.

\section{Acknowledgments}

We would like to thank Dr.A.Akkerman and Dr.J.Va'vra for stimulating discussions.

This work was supported by the Foundation Mordoh Mijan de Salonique, the Basic Research Foundation of the Israel Academy of Sciences and Humanities, the United StatesIsrael Binational Science Foundation (BSF), the Commission of the European Communities and the Israel Ministry of Science and Arts. A.Breskin is the W.P.Reuther Professor of Research in the peaceful uses of atomic energy. A.Buzulutskov is grateful to A.Breskin for his support.

\section{Appendix}

\section{Quantum yield of coated photocathodes}

Let us consider, as an example, the CsI photocathode coated with a LiF film. Fig. 2 shows a simplified energy diagram at the $\mathrm{CsI} / \mathrm{LiF} /$ vacuum interface. If the initial electron energy distribution $d N / d E$ in CsI and the final electron energy distribution $d N / d E^{\prime}$ in LiF near the surface are assumed constant, then a relation between them, as well as between initial $E$ and final $E^{\prime}$ electron energies, should be linear:

$$
d N / d E=g d N / d E^{\prime} . \quad E^{\prime}=y E .
$$


where the factor $g$ depends on the LiF thickness. Let $E_{m}$ and $E_{m}^{\prime}=g E_{m}$ be the initial and final maximum electron energies, and $\Delta E$ the initial energy interval within which they are distributed: $\Delta E=h \nu-E_{g}(\mathrm{CsI})$, where $h \nu$ is the photon energy and $E_{g}(\mathrm{CsI})$ the energy gap of CsI.

The escape probability of an electron with energy $E$ over the potential barrier $E_{0}$ is [81]:

$$
P(E)=\frac{1}{2}\left[1-\left(E_{0} / E\right)^{1 / 2}\right] .
$$

Assuming that one absorbed photon produces one electron in the CsI conduction band, then the quantum yield (QY) of the photoemission from $\mathrm{CsI} / \mathrm{LiF}$ film is given by

$$
\begin{aligned}
Y= & f_{1} \frac{\int_{E_{0}}^{E_{m}^{\prime}} d N / d E^{\prime} P\left(E^{\prime}\right) d E^{\prime}}{\int_{E_{m}-\Delta E}^{E_{m}} d N / d E d E}= \\
= & \frac{f}{2 \Delta E}\left[g^{1 / 2} E_{m}^{1 / 2}-E_{0}^{1 / 2}\right]^{2}
\end{aligned}
$$

Here $f_{1}$ and $f$ are the normalization factors depending on the LiF thickness; $E_{0}$, measured from the bottom of the $\mathrm{LiF}$ conduction band, is simply equal to the LiF electron affinity $E_{a}(\mathrm{LiF})$. Both $E_{m}$ and $E_{0}$ should be measured from the same energy level. The relation between them, assuming a non-modification of the surface barrier due to LiF coating as discussed in section 3.2, is as follows: $E_{m}=\Delta E+E_{0}-E_{a}(\mathrm{CsI})$.

We have only two parameters in the model, $f$ and $g$, which in fact describe the electron transport properties through LiF film. All these expressions are also valid for $\mathrm{CsI} / \mathrm{NaF}$ and other films. The model is not sensitive to the absolute value of the $\mathrm{LiF}$ or NaF electron affinity since it is automatically accounted for by $f$ and $g$. For the energy gap and electron affinity of CsI, the values $E_{g}(\mathrm{CsI})=5.9 \mathrm{eV}$ and $E_{u}(\mathrm{CsI})=0.2 \mathrm{eV}$ were used, derived from recent data on CsI absorption spectra [26] and field-enhanced photoemission [66]. 


\section{References}

[1] V.Dangendorf, A.Breskin, R.Chechik and H.Schmidt-Böcking, Nucl. Instr. and Meth. A 289, $322(1990)$.

[2] G.Charpak, V.Peskov, D.Scigocki and V.Valbis, Proc. of the Int. Simp. on Particle Identification at High Luminosity Hadron Colliders, edited by T.G.Gouraly and I.G.Morfin (FNAL, IL, USA, 1989), p.295.

[3] J.Seguinot, G.Charpak, Y.Giomataris, V.Peskov, J.Tischhauser and T.Ypsilantis, Nucl. Instr. and Meth. A 297, 133 (1990).

[4] A.Breskin, Nucl. Instr. and Meth. A 371, 116 (1996), and references therein.

[5] See for example in the Proc. of the 1st Int. Workshop on RICH Detectors, Bari, Italy, June 2-5, 1993, Nucl. Instr. and Meth. A 343, 1-326 (1994), and references therein.

[6] G.Charpak, W.Dominik, F.Sauli, and S.Majewski, IEEE Trans. Nucl. Sci. 30, 134 (1983).

[7] J.S.Edmends and D.J.Miller, Nucl. Instr. and Meth. A 273, 145 (1988).

[8] V.Peskov, A.Borovik-Romanov, T.Sokolova, and E.Silin, Nucl. Instr. and Meth. A 353, 184 (1994).

[9] A.Breskin, A.Buzulutskov, and R.Chechik, IEEE Trans. Nucl. Sci. 42, 298 (1995).

[10] A.Buzulutskov, A.Breskin, R.Chechik, and J.Va'vra, Nucl. Instr. and Meth. A 371, 147 (1996).

[11] A.Akkerman, A.Breskin, R.Chechik, and A.Gibrekhterman, in Ionization of Solids by Heavy Particle, edited by R.A.Baragiola (Plenum, New York, 1993), p.359.

[12] R.P.Madden, in Physics of thin films, edited by G.Hass (Academic, New York, 1963), v.1, p.123.

[13] E.Ritter, in Physics of Thin Films, edited by G.Hass, M.F.Francombe, R.W.Hoffman (Academic, New York, 1975), v.8, p.1.

[14] M.Grundner and H.Jacob, Appl. Phys. A 39, 73 (1986).

[15] H.Yao and J.A.Woollam, Appl. Phys. Lett. 62, 3324 (1993).

[16] M.P.Seah and W.A.Dench, Surf. Interface Anal. 1, 1 (1979).

[17] J.Llacer and E.L.Garwin, J. Appl. Phys. 40, 2766 (1969).

[18] A.Akkerman, T.Boutboul, A.Breskin, and R.Chechik, J. Appl. Phys. 76, 4656 (1994).

[19] S.W.Duckett and P.H.Metzger, Phys. Rev. 137, A953 (1965).

[20] W.Pong, J. Appl. Phys. 37, 3033 (1966).

[21] W.Pong, J. Appl. Phys. 40, 1733 (1969).

[22] A.D.Bayer and G.J.Lapyere, Phys. Rev. Lett. 31, 304, 1973.

[23] F.R.McFeely, E.Cartier, J.A.Yarmoff, and S.A.Joyce, Phys. ReV. B 42, 5191 (1990).

[24] P.Pfluger, H.R.Zeller, and J.Bernasconi, Phys. Rev. Lett. 53, 94 (1984).

[25] A.Kadyshevitch and R.Naaman, Phys. Rev. Lett. 74, 3443 (1994).

[26] C.Lu and K.T.McDonald, Nucl. Instr. Meth. A 343, 135 (1994).

[27] N.Schwentner, Phys. Rev. B 14, 5490 (1976).

[28] G.Bader, G.Perluzzo, L.G.Caron, L.Sanche, Phys. Rev. B 26, 6019 (1982).

[29] E.M.Gullikson and B.L.Henke, Phys. Rev. B 39, 1 (1989).

[30] S.D.Brorson, D.J.DiMaria, M.V.Fischetti, F.L.Pesavento, P.M.Solomon, and D.W.Dong, J. Appl. Phys. 58, 1302 (1985), and references therein.

[31] J.F.Verwey, E.A.Amerasekera, and J.Bisschop, Rep. Prog. Phys. 53, 1297 (1990), and references therein.

[32] D.G.Esaev, V.M.Efimov, and A.A.Shklyaev, Thin Solid Films 221, 160 (1992). 
[33] J.N.Bradford and S.Woolf, Proc. of the Second Europ. Conf. Radiat. Eff. Comp. Syst. (RADECS 93), 13-16 Sept 1993, St.Malo, France (IEEE, New York, 1994), p.161, and references therein.

[34] R.M.Handy, J. Appl. Phys. 37, 4620 (1966).

[35] E.D.Savoye and D.E.Anderson, J. Appl. Phys. 38, 3245 (1967).

[36] A.Buzulutskov, A.Breskin, and R.Chechik, Nucl. Instr. and Meth. A 372, 572 (1996).

[37] L.Heroux, W.J.McMahon, and H.E.Hinteregger, Appl. Opt. 5, 1338 (1966).

[38] A.H.Sommer, RCA Rev. 28, 75 (1967).

[39] A.Breskin, A.Buzulutskov, R.Chechik, M.Prager, and E.Shefer, Appl. Phys. Lett. 69, 1008 (1996).

[40] A.Breskin, A.Buzulutskov, R.Chechik, and E.Shefer, ICFA Instrum. Bulletin, SLAC-PUB$7175,29(1996)$.

[41] A.Buzulutskov, A.Breskin, R.Chechik, M.Prager, and E.Shefer, Protection of cesium-antimony photocathodes, Preprint WIS-96/22/Jun-PH, to be published in Nucl. Instr. and Meth. A.

[42] A.Breskin, A.Buzulutskov, R.Chechik, D.Vartsky, G.Malamud, and P.Miné, Nucl. Instr. and Meth. A 344, 537 (1994).

[43] A.Breskin, R.Chechik, D.Vartsky, G.Malamud, and P.Miné, Nucl. Instr. and Meth. A 343, 159 (1994).

[44] A.Buzulutskov, A.Breskin, and R.Chechik, Nucl. Instr. and Meth. A 366, 410 (1995).

[45] Sycon Instruments, STM-100.

[46] U.Kaiser, N.Kaiser, P.Weisbrodt, U.Mademann, E.Hacker, and H.Muller, Thin Solid Films 217, 7 (1992).

[47] Alfa, Johnson Matthey GmbH.

[48] R.Glang, in Handbook of Thin Film Technology, edited by L.I.Maissel and R.Glang (McGrawHill, New York, 1983), pp. 1-80 - 1-85.

[49] Panametrics, PDH-332-110.

[50] J.G.Simmons, in Handbook of Thin Film Technology, edited by L.I.Maissel and R.Glang (McGraw-Hill, New York, 1983), pp. 14-4 - 14-12.

[51] D.S.Campbell and A.R.Morley, Rep. Prog. Phys., 34, pp. 309-314 (1971).

[52] J.Almeida, F.Barbo, M.Bertolo, A.Bianco, A.Braem, S.Cerasari, C.Coluzza, T.dell'Orto, S.Fontana, G.Margaritondo, E.Nappi, G.Paic, F.Piuz, R.Sanjines, T.Scognatti, and S.Sgobba, Nucl. Instr. and Meth. A 361, 524 (1995).

[53] J.Almeida, A.Braem, A.Breskin, A.Buzulutskov, R.Chechik, S.Cohen, C.Coluzza, E.Conforto, G.Margaritondo, E.Nappi, G.Paic, F.Piuz, T.dell'Orto, T.Scognetti, S.Sgobba, and B.P.Tonner, Nucl. Instr. and Meth. A 367, 337 (1995).

[54] W.M.K.P.Wijekoon, M.Y.M.Lyktey, P.N.Prasad, and J.F.Garvey, J. Appl. Phys. 74. 5767 (1993).

[55] L.A.Ageev, V.K.Miloslavskii, and T.I.Maksimenko, Soviet Phys. Solid State 16, 1873 (1975).

[56] T.Sauder, A.Daunois, J.L.Deiss, and J.C.Merle, Solid State Commun. 51, 323 (1984).

[57] E.T.Hutcheson, G.Hass, and J.T.Cox, Appl. Opt. 11, 2245 (1972).

[58] B.E.Evans, L.W.Swanson, and A.E.Bell, Surface Sci. 11, 1 (1968).

[59] S.Garbe, Phys. Stat. Sol. (a) 2, 497 (1970).

[60] E.A.Taft and H.R.Philipp, J. Phys. Chem. Solids, 3, 1 (1957).

[61] M.Kamada, O.Aita, K.Ichikawa, and K.Tsutsumi, Phys. Rev. B 36, 4962 (1987).

[62] J.B.Boyce and B.A.Huberman, Physics Rep. 51, 189 (1979). 
[63] D.Gerstenberg, in Handbook of Thin Film Technology, edited by L.I.Maissel and R.Glang (McGraw-Hill, New York, 1983), p. 19-1.

[64] Y.Iguchi, Sci. Light 13, 37 (1964).

[65] M. Rei Vilar, G.Blatter, P.Pfluger, M.Heyman, and M.Schott, Europhysics Lett. 5, 375 (1988), and references therein.

[66] A.Buzulutskov, A.Breskin, and R.Chechik, J. Appl. Phys. 77, 2138 (1995).

[67] Landolt-Börnstein, Numerical Data and Functional Relationships in Science and Technology, (Springer-Verlag, Berlin), v. III/7a, pp. 10, 14, 592-594; v. III/22a, pp. 250-252; v. III/23a, pp. 113-114.

[68] C.Jouanin, J.P.Albert, and C.Gout, J. Phys. 37, 595 (1976).

[69] V.A.Ganin et al., Sov. Phys. Solid State 16, 2313 (1975).

[70] F.G.Allen and G.W.Gobeli, Phys. ReV. 144, 558 (1966).

[71] A.H.Sommer, Photoemissive Materials (R.E.Krager Publ. Co., Huntington, 1980), chapter 13 , and references therein; p.220.

[72] A.Modinos, Field, Thermionic and Secondary Electron Emission Spectroscopy (Plenum Press, New York, 1984), chapter 6, and references therein.

[73] P.B.Barraclough and P.G.Hall, Surf. Sci. 46, 393 (1974).

[74] J.Estel, H.Hoinkes, H.Kaarmann, H.Nahr, and H.Wilsch, Surf. Sci. 54, 393 (1976).

[75] S.Fölsch, A.Stock, and M.Henzler, Surf. Sci. 264, 65 (1992).

[76] J.C.Zink, J.Reif, and E.Matthias, Phys. Rev. Lett. 68, 3595 (1992).

[77] P.Tepper, J.C.Zink, H.Schmelz, B.Wassermann, J.Reif, and E.Matthias, J. Vac. Sci. Technol. B 7, $1212(1989)$.

[78] B.Wassermann, S.Mirbt, J.Reif, J.C.Zink, and E.Matthias, J. Chem. Phys. 98, 10049 (1993).

[79] R.Popovitz-Biro, J.Majewski, J.L.Wang, L.Leiserowitz, and M.Lahav, in Thin Films, edited by A.Ulman (Academic, San Diego, 1995), v. 20, p. 145, and references therein.

[80] C.N.Berglung and W.E.Spicer, Phys.Rev. 4A, pp. A1030 and A1044 (1964), and references therein.

[81] F.Wooten and R.N.Stuart, Phys. Rev. 186, 592 (1969).

[82] W.E.Pickett, Phys. Rev. Lett. 73, 1664 (1994), and references therein. 


\section{Figure captions}

Fig.1 Experimental setup. a) Photocathode evaporation and characterization. b) Heat treatment of the sample. c) Exposure to water vapour and ambient air.

Fig.2 Simplified energy-band diagram at the CsI/LiF/vacuum interfaces, before and after exposure to water vapour. $E_{a}(\mathrm{CsI})$ and $E_{a}(\mathrm{LiF})$ are the initial electron affinities of CsI and LiF respectively.. The photoemission process is depicted schematically as well.

Fig.3 Atomic force microscopy (AFM) images of uncoated CsI (bottom) and CsI coated with $20 \AA$ thick LiF film (top).

Fig.4 Absolute quantum yield spectra of $\mathrm{CsI}$ and $\mathrm{CuI}$ photocathodes coated with dielectric films of $\mathrm{LiF}, \mathrm{MgF}_{2}, \mathrm{CsF}$ and $\mathrm{NaI}$. The thicknesses of the coating film are indicated. Dot-dashed lines in plots for $\mathrm{CsI} / \mathrm{NaI}$ and $\mathrm{CuI} / \mathrm{NaI}$ represent the quantum yield spectra of $\mathrm{NaI}$ films, of a thickness of $100 \AA$ and $500 \AA$ respectively, deposited on stainless steel substrates.

Fig.5 Absolute quantum yield of $\mathrm{CsI} / \mathrm{LiF}$ photocathodes as a function of thickness of the coating film, measured at different wavelengths. Solid lines are the exponential fits to the data points.

Fig.6 Absolute quantum yield of $\mathrm{CsI} / \mathrm{CsF}$ photocathodes as a function of thickness of the coating film, measured at different wavelengths.

Fig.7 Absolute quantum yield of $\mathrm{CsI} / \mathrm{NaI}$ photocathodes, after subtraction of the photoemission of NaI, as a function of thickness of the coating film, measured at different wavelengths. Solid lines are the exponential fits to the data points.

Fig.8 Absolute quantum yield of $\mathrm{CsI} / n-\mathrm{C}_{36} \mathrm{H}_{74}$ photocathodes as a function of thickness of the coating film, measured at different wavelengths. Solid lines are the exponential fits to the data points.

Fig.9 Absolute quantum yield of CsI photocathodes coated with various films LiF, $\mathrm{NaF}$, $\mathrm{CsF}, \mathrm{NaI}, \mathrm{MgF}_{2}, \mathrm{SiO}_{2}, \mathrm{Al}_{2} \mathrm{O}_{3}$ and $n-\mathrm{C}_{36} \mathrm{H}_{74}$ (HTC), as a function of the film thickness, measured at $170 \mathrm{~nm}$ (points). Solid lines are the exponential fits to the data points (points at zero thickness are excluded from the fit).

Fig.10 Attenuation length of the photoyield in $\mathrm{LiF}, \mathrm{NaF}, \mathrm{CsF}, \mathrm{NaI}, \mathrm{MgF} 2, \mathrm{SiO}, \mathrm{SiO}_{2}$, $\mathrm{Al}_{2} \mathrm{O}_{3}$ and $n-\mathrm{C}_{36} \mathrm{H}_{74}$ films deposited on $\mathrm{CsI}$, and in $\mathrm{CsF}$ film deposited on $\mathrm{CuI}$, as a function of the photon energy.

Fig.11 a) Evolution of the quantum yield during the exposure test of a CsI/LiF photocathode to humid air. Quantum yield spectra are shown for: (1) uncoated CsI; (2) CsI coated with $22 \AA$ thick LiF film; (3) 22 hours exposure to 1 atm of humid air with $\mathrm{H}_{2} \mathrm{O}$ pressure of about 10 Torr, at room temperature inside the evaporation chamber; 
(4) 3 days exposure to high vacuum; (5) further heating in vacuum at $60^{\circ} \mathrm{C}$ for 2 hours; (6) 33 days storing in ambient air.

b) Evolution of the quantum yield during the exposure test of a CsI/LiF photocathode to $\mathrm{H}_{2} \mathrm{O}$ vapour in vacuum. Quantum yield spectra are shown for: (1) uncoated CsI, (2) CsI coated with $\geq 15 \AA$ thick $\mathrm{LiF}$ film, (3) 2 min at 0.3 Torr $\mathrm{H}_{2} \mathrm{O}$, (4) further 4 min at 1 Torr $\mathrm{H}_{2} \mathrm{O},(5)$ further 10 min at 7 Torr $\mathrm{H}_{2} \mathrm{O}$, (6) further 2 hours at 7 Torr $\mathrm{H}_{2} \mathrm{O}$.

Fig.12 Quantum yield spectra of CsI/LiF photocathodes for LiF thicknesses $10 \AA$, before and after exposure to 1 atm of humid air with $\mathrm{H}_{2} \mathrm{O}$ pressure of about 10 Torr, for 20 hours. The quantum yield of CsI before coating is shown as well. Points are experimental data, curves are model fits.

Fig.13 Water dosage dependence of the quantum yield of CsI/LiF (LiF thickness $\geq 15 \AA$ ), $\mathrm{CsI} / \mathrm{NaF}(\mathrm{NaF}$ thickness $15 \AA$ ) and $\mathrm{CsI} / \mathrm{CsF}$ (CsF thickness $44 \AA$ ) photocathodes. Exposure to $\mathrm{H}_{2} \mathrm{O}$ vapour was done in vacuum for $\mathrm{CsI} / \mathrm{LiF}$ and in air for $\mathrm{CsI} / \mathrm{NaF}$ and $\mathrm{CsI} / \mathrm{CsF}$.

Fig.14 Quantum yield spectra of CsI photocathodes coated with (a) hygroscopic films of $\operatorname{LiF}(22 \AA), \operatorname{NaF}(23 \AA), \operatorname{CsF}(102 \AA)$ and (b) with nonhygroscopic films of $\mathrm{MgF}_{2}(22$ $\AA$, heat treated [9]), $\mathrm{BaF}_{2}(28 \AA)$, before and after exposure to $1 \mathrm{~atm}$ of humid air, at room temperature inside the evaporation chamber. Exposure time and $\mathrm{H}_{2} \mathrm{O}$ pressure were respectively $30 \mathrm{~min}$ and 10 Torr for $\mathrm{CsF}, 5 \mathrm{~min}$ and 6 Torr for $\mathrm{NaF}, 22$ hours and about 10 Torr for LiF, 16 hours and 11.5 Torr for $\mathrm{MgF}_{2}, 5$ min and 7 Torr for $\mathrm{BaF}_{2}$. A typical quantum yield spectrum of an uncoated CsI photocathode is shown as well. 
Table I: Film preparation conditions.

\begin{tabular}{|c|c|c|c|c|c|}
\hline $\begin{array}{l}\text { Deposited } \\
\text { material }\end{array}$ & $\begin{array}{l}\text { Purity } \\
\%\end{array}$ & $\begin{array}{l}\text { Evaporation } \\
\text { source }\end{array}$ & $\begin{array}{l}\text { Substr. } \\
\text { temp. } \\
{ }^{\circ} \mathrm{C} \\
\end{array}$ & $\begin{array}{l}\text { Deposition } \\
\text { rate } \\
\AA / \mathrm{sec} \\
\end{array}$ & Remarks \\
\hline CsI & ultrapure & Mo boat & 60 & $50-120$ & \\
\hline $\mathrm{CuI}$ & ultrapure & Mo,Ta boat & 70 & $10-25$ & Poor quality for higher rate. \\
\hline $\mathrm{LiF}$ & \begin{tabular}{|l}
99.99 \\
99.9 \\
\end{tabular} & $\begin{array}{l}\text { Mo,Ta boat } \\
\text { with cover }\end{array}$ & 60 & $0.05-0.1$ & Poor quality for higher rate. \\
\hline $\mathrm{NaF}$ & $\begin{array}{l}99.995 \\
99 \\
\end{array}$ & $\begin{array}{l}\text { Mo boat } \\
\text { with cover }\end{array}$ & 70 & $0.1-1$ & Poor quality for $99 \%$ purity. \\
\hline $\mathrm{CsF}$ & 99.9 & $\begin{array}{l}\text { Mo boat } \\
\text { with cover }\end{array}$ & 22 & $0.1-1$ & \\
\hline $\mathrm{NaI}$ & 99.5 & $\begin{array}{l}\text { Ta boat } \\
\text { with cover }\end{array}$ & 70 & $0.5-1.5$ & Poor quality for rate $5 \AA / \mathrm{sec}$. \\
\hline $\mathrm{MgF}_{2}$ & 99.99 & $\begin{array}{l}\text { Mo boat } \\
\text { with cover }\end{array}$ & 60 & $0.2-0.8$ & \\
\hline $\mathrm{BaF}_{2}$ & opt.grade & $\begin{array}{l}\text { Mo, Ta boat } \\
\text { with cover }\end{array}$ & 60 & $0.2-0.3$ & Not well reproducible. \\
\hline $\mathrm{SiO}$ & 99.9 & baffle Ta box & 90 & $0.05-0.1$ & Poor quality for higher rate. \\
\hline $\begin{array}{l}\mathrm{SiO}_{2} \\
\text { 1) }\end{array}$ & $\begin{array}{l}\mathrm{SiO}, 99.8 \\
\text { quartz }\end{array}$ & $\begin{array}{l}\text { Mo boat } \\
\text { with cover } \\
\text { electron beam }\end{array}$ & 22 & $\begin{array}{l}0.1-0.5 \\
0.3-1\end{array}$ & $\begin{array}{l}\text { Reactive evaporation of } \mathrm{SiO} \text { at } \\
(1-3) \times 10^{-4} \text { Torr } \mathrm{O}_{2} \text {. Weak } \\
\text { Si XPS-signal for lower rate. }\end{array}$ \\
\hline $\begin{array}{l}\mathrm{Al}_{2} \mathrm{O}_{3} \\
\text { 1) } \\
\text { 2) }\end{array}$ & $\begin{array}{l}\text { Al, } 99.98 \\
\text { sapphire }\end{array}$ & $\begin{array}{l}\text { W wire } \\
\text { electron beam }\end{array}$ & $\begin{array}{l}22 \\
22\end{array}$ & $\begin{array}{l}0.3-6 \\
1\end{array}$ & $\begin{array}{l}\text { Reactive evaporation of } \mathrm{Al} \\
\text { at }(0.5-1.6) \times 10^{-4} \text { Torr } \mathrm{O}_{2} \text {. }\end{array}$ \\
\hline$n-\mathrm{C}_{36} \mathrm{H}_{74}$ & 99 & $\begin{array}{l}\text { Ta boat } \\
\text { with cover }\end{array}$ & 22 & $0.5-1.5$ & \\
\hline
\end{tabular}


Table II: Lattice constants $a$ and $c$, energy gap $E_{g}$ and electron affinity $E_{a}$ of the film materials used in the present work. Data on $E_{g}$ for CsI and on $E_{a}$ for CsI and CuI are given for the heat-treated films ${ }^{a}$; for $\mathrm{NaI}$ the $E_{\mathrm{a}}$ is given for a fresh (non heat-treated) film ${ }^{b}$. For other films the data are compiled from elsewhere ${ }^{c}$.

\begin{tabular}{l|llllll}
\hline \hline Material & CsI & $\mathrm{CuI}$ & $\mathrm{LiF}$ & $\mathrm{NaF}$ & $\mathrm{CsF}$ & $\mathrm{NaI}$ \\
\hline$a[\AA]$ & 4.57 & 6.04 & 4.03 & 4.62 & 6.02 & 6.47 \\
$E_{g}[\mathrm{eV}]$ & 5.9 & 3.0 & $\geq 12$ & 11.5 & 10.0 & 5.8 \\
$E_{a}[\mathrm{eV}]$ & 0.2 & 2.5 & $\leq 1$ & - & - & 1.4 \\
\hline \hline Material & $\mathrm{MgF}_{2}$ & $\mathrm{BaF}_{2}$ & $\mathrm{SiO}_{2}$ & $\mathrm{Al}_{2} \mathrm{O}_{3}$ & $n-\mathrm{C}_{36} \mathrm{H}_{74}$ & \\
\hline$a, c[\AA]$ & $4.62,3.05$ & 6.20 & - & - & - & \\
$E_{g}[\mathrm{eV}]$ & $\geq 14$ & 11 & 8.8 & 7 & 8.8 & \\
$E_{a}[\mathrm{eV}]$ & - & - & 0.9 & 1 & -0.5 & \\
\hline \hline
\end{tabular}

a) Refs. $[44,66]$

b) Ref. [44]

c) Refs. $[71,67,68,69,31,21,65]$

Table III: Model estimations of the electron affinity reduction due to $\mathrm{H}_{2} \mathrm{O}$ adsorption.

\begin{tabular}{ll}
\hline \hline Film & $\Delta E_{a}[\mathrm{eV}]$ \\
\hline $\mathrm{CsI} / \mathrm{LiF}(6 \AA)$ & $0.17 \pm 0.01$ \\
\hline $\mathrm{CsI} / \mathrm{LiF}(10 \AA)$ & $0.32 \pm 0.01$ \\
\hline $\mathrm{CsI} / \mathrm{LiF}(22 \AA)$ & $0.35 \pm 0.04$ \\
\hline $\mathrm{CsI} / \mathrm{NaF}(7 \AA)$ & $0.15 \pm 0.01$ \\
\hline $\mathrm{CsI} / \mathrm{NaF}(23 \AA)$ & $0.37 \pm 0.05$ \\
\hline \hline
\end{tabular}




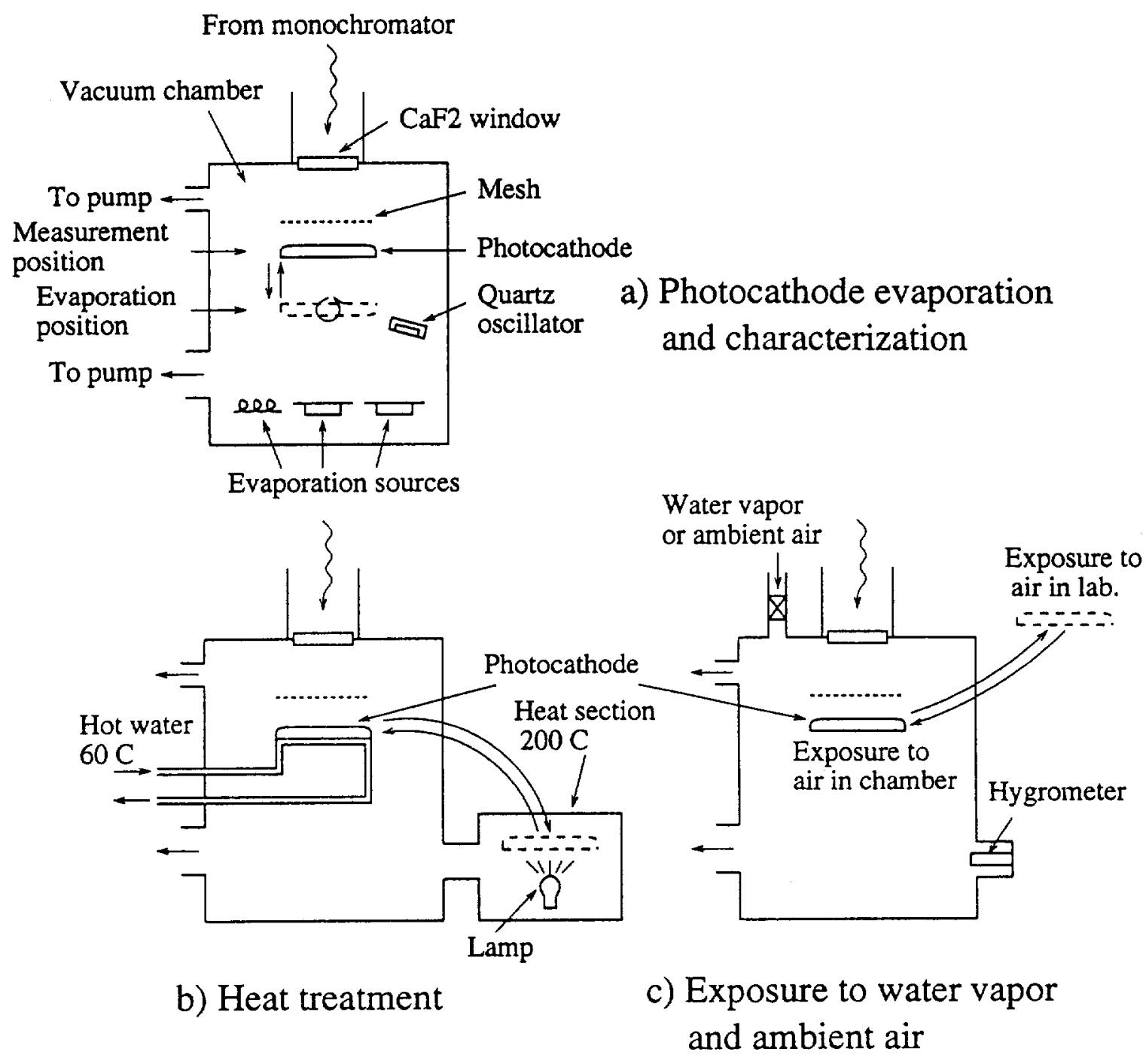

Fig.1 


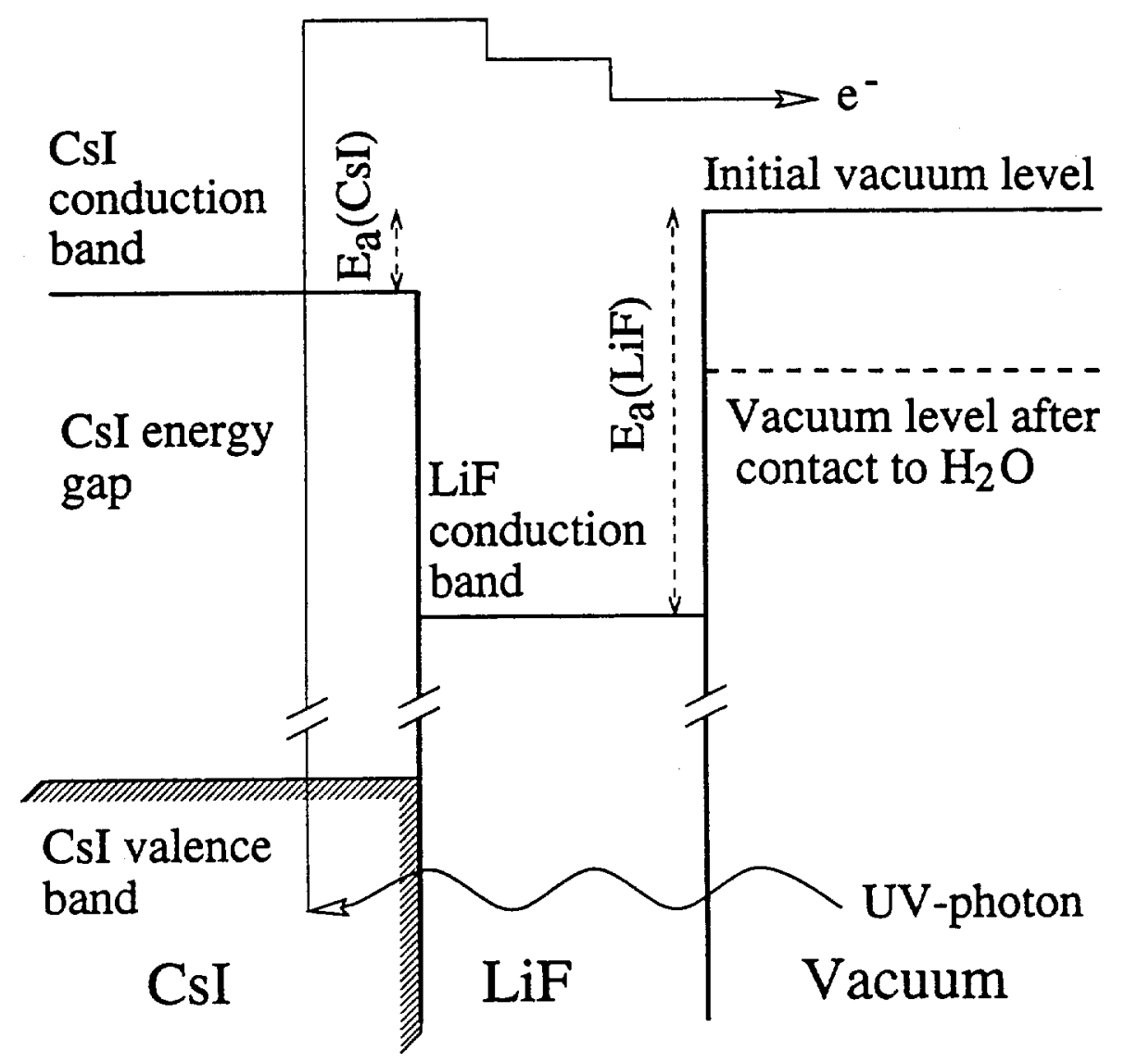

Fig.2 

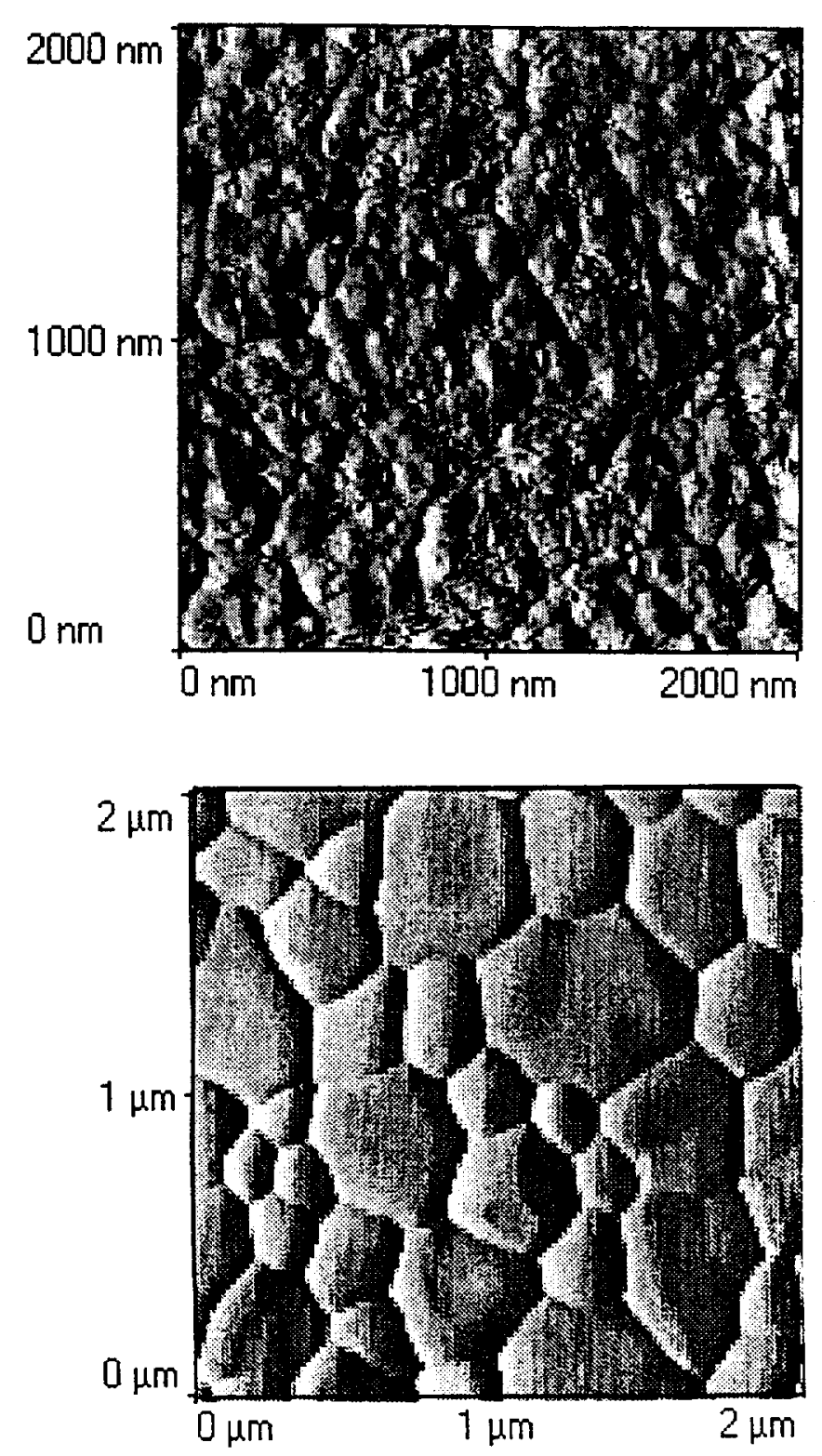

Fig.3 

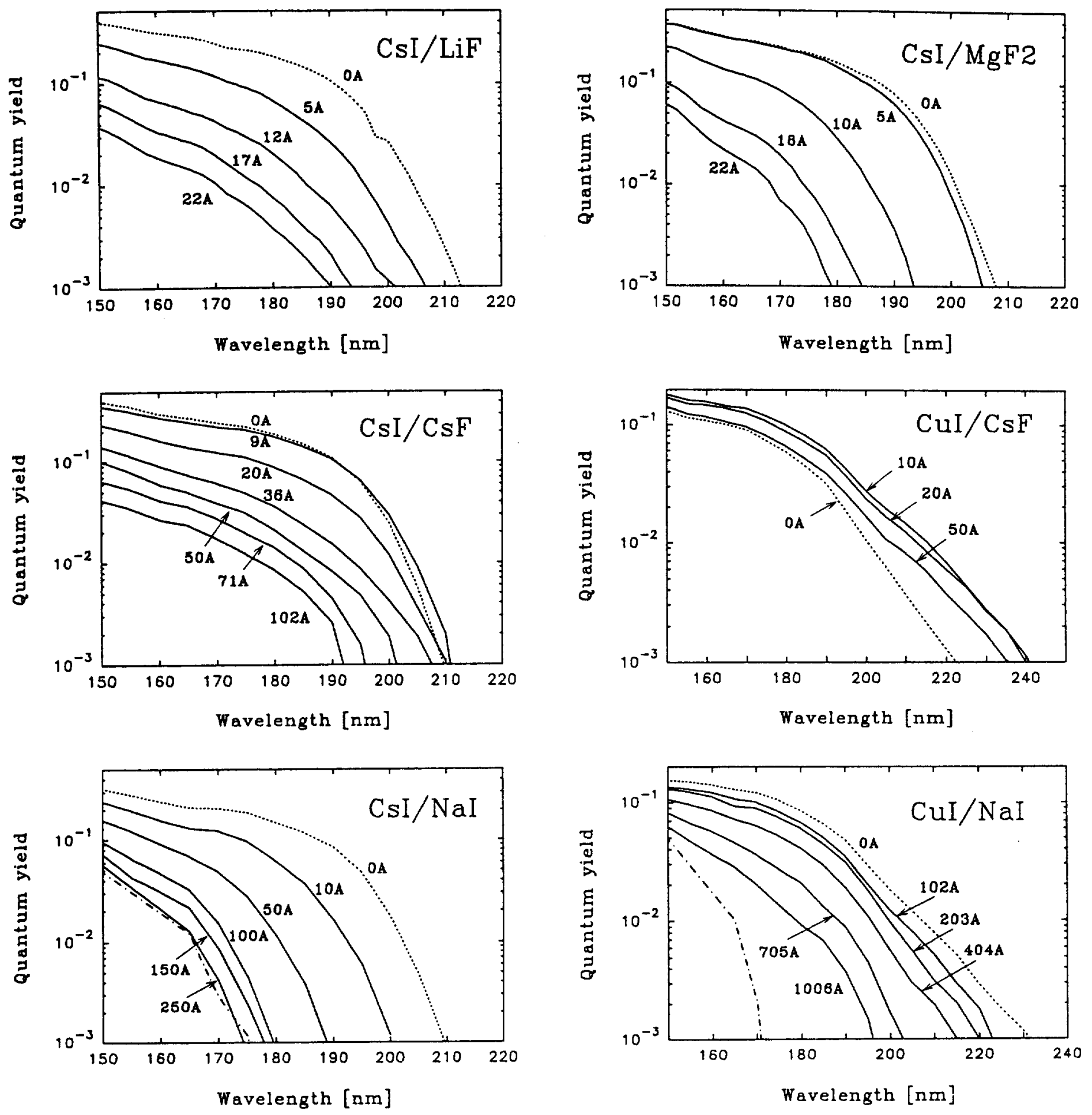

Fig.4 


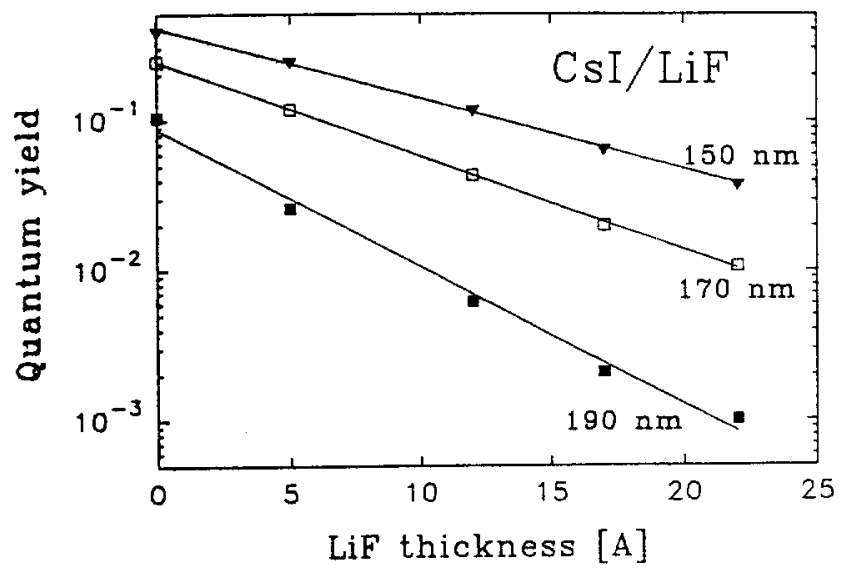

Fig.5

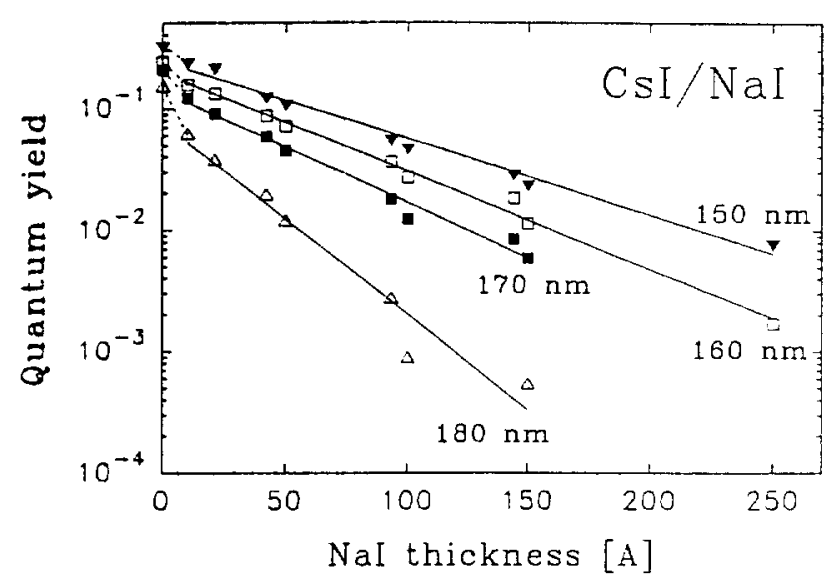

Fig.7

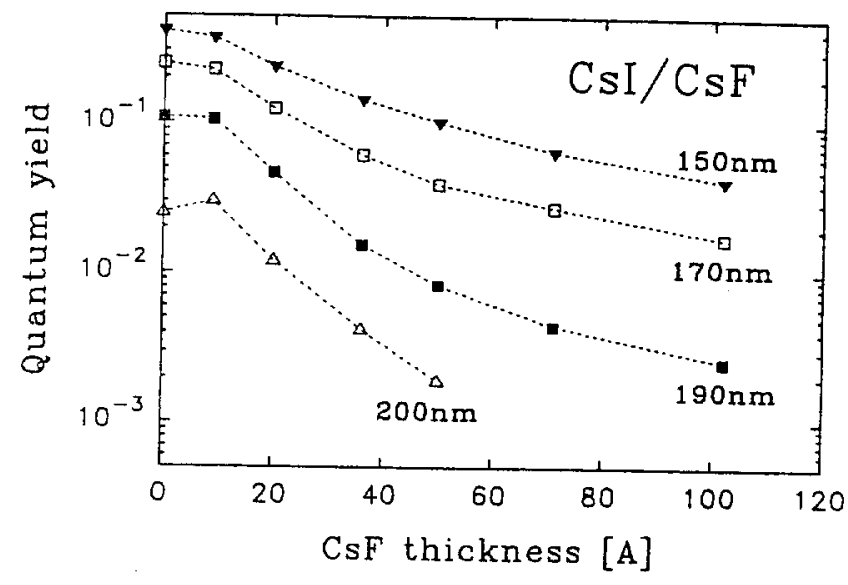

Fig.6

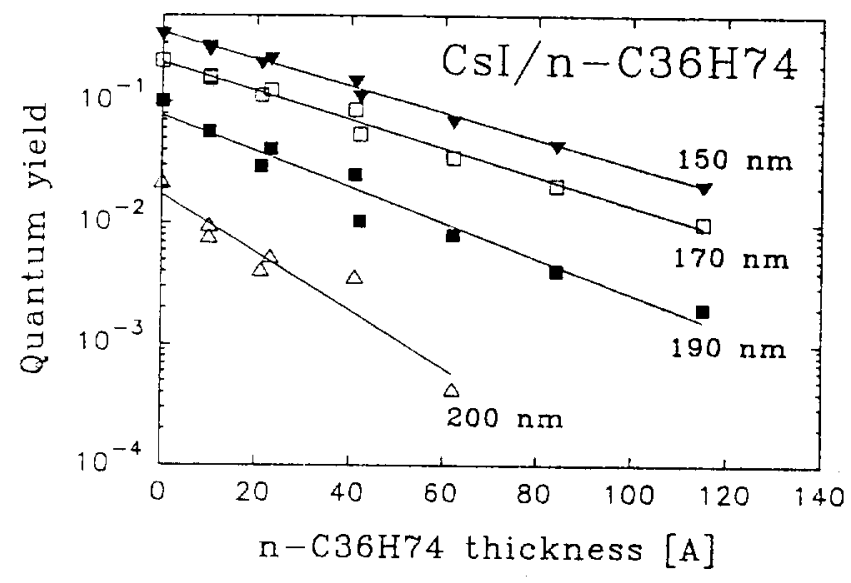

Fig. 8 


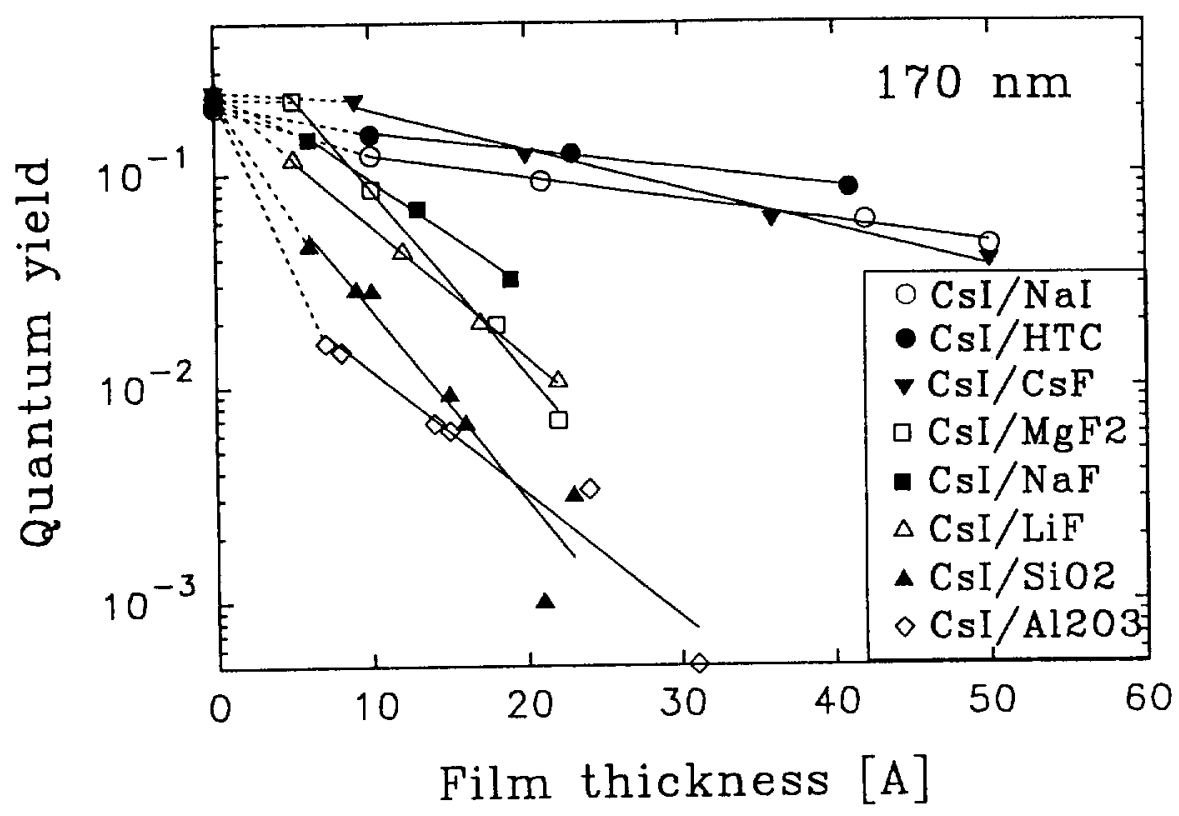

Fig.9

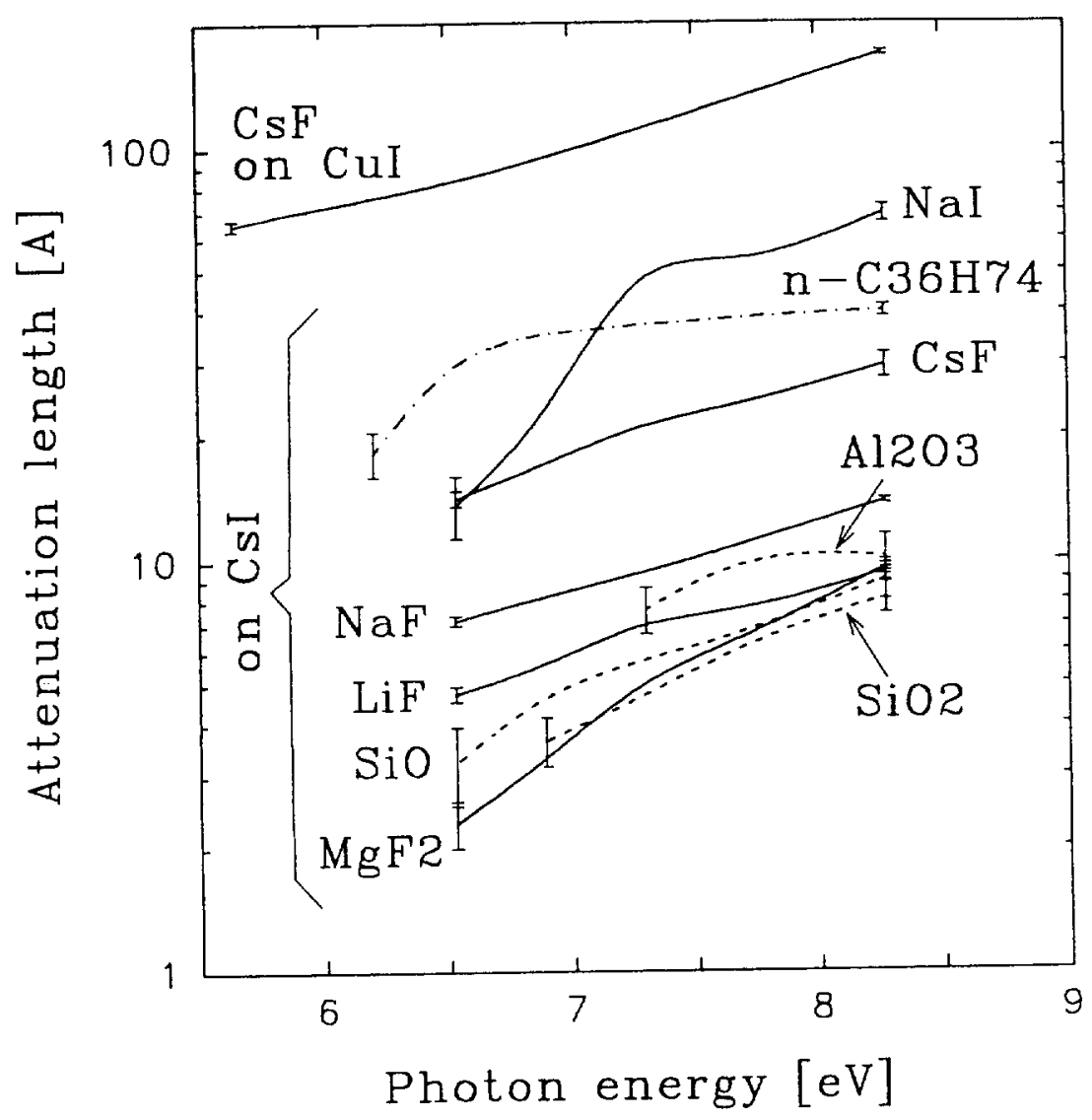

Fig.10 


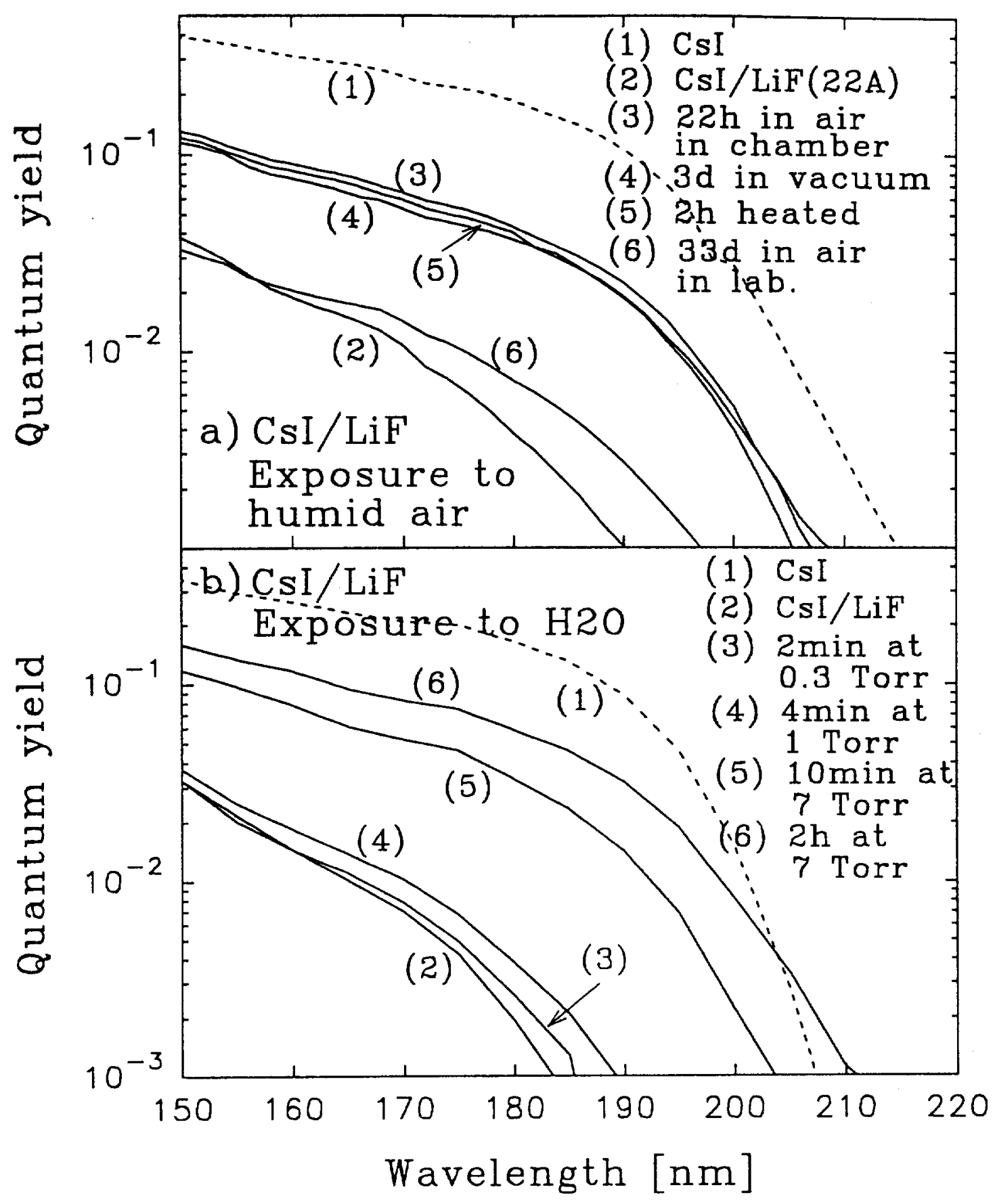

Fig.11 


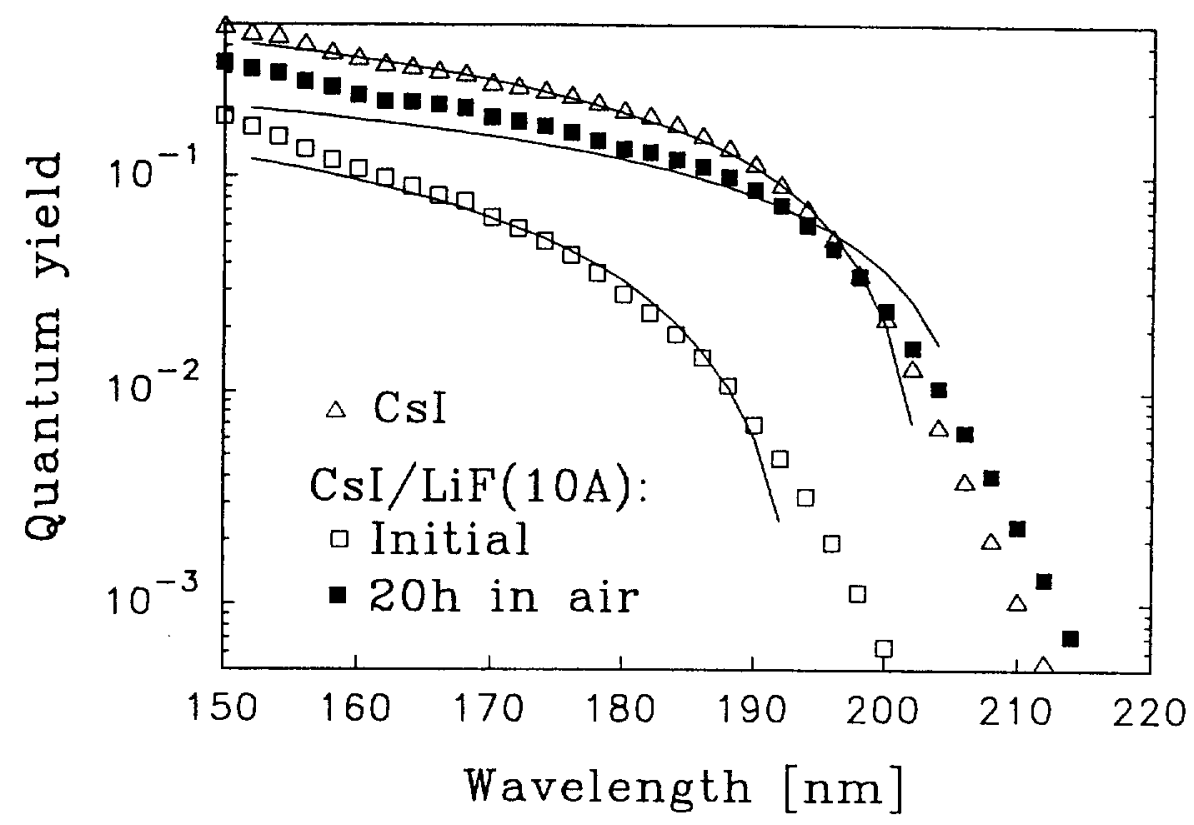

Fig.12

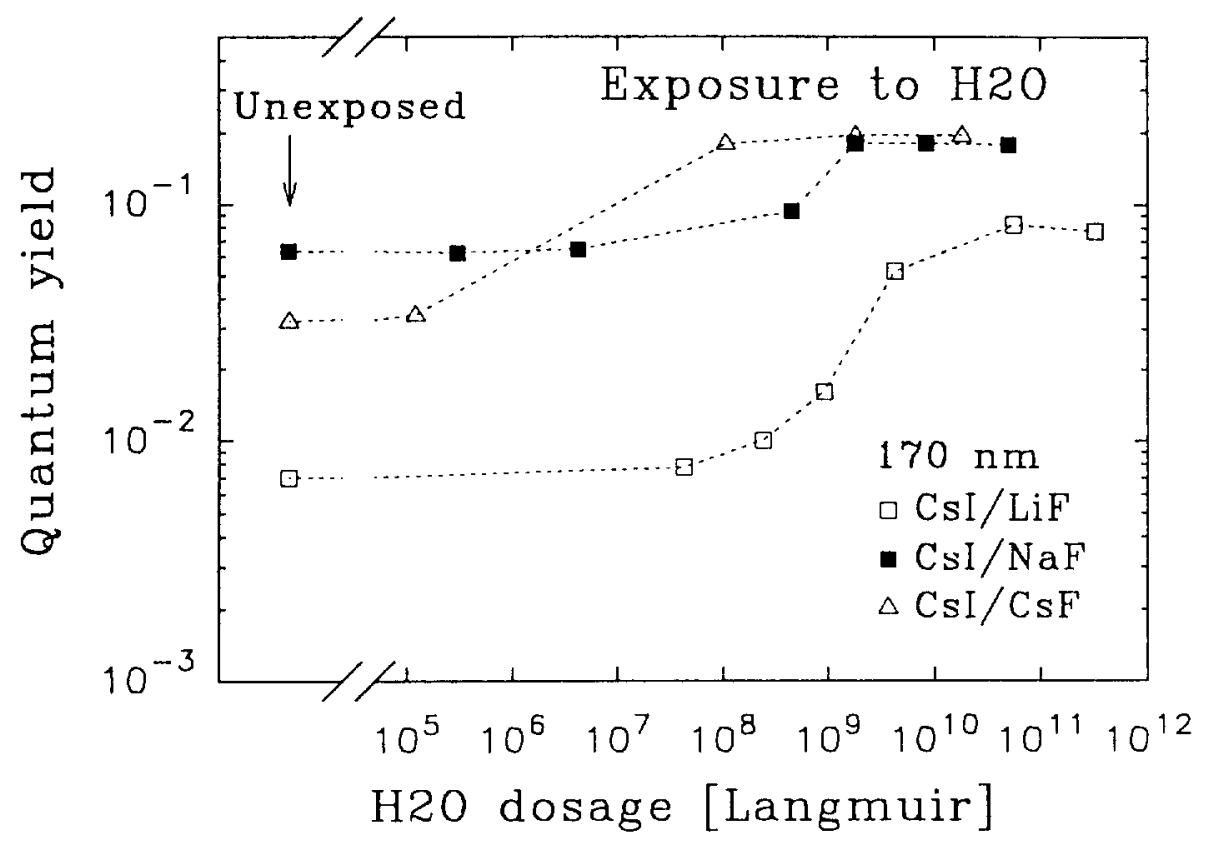

Fig.13 


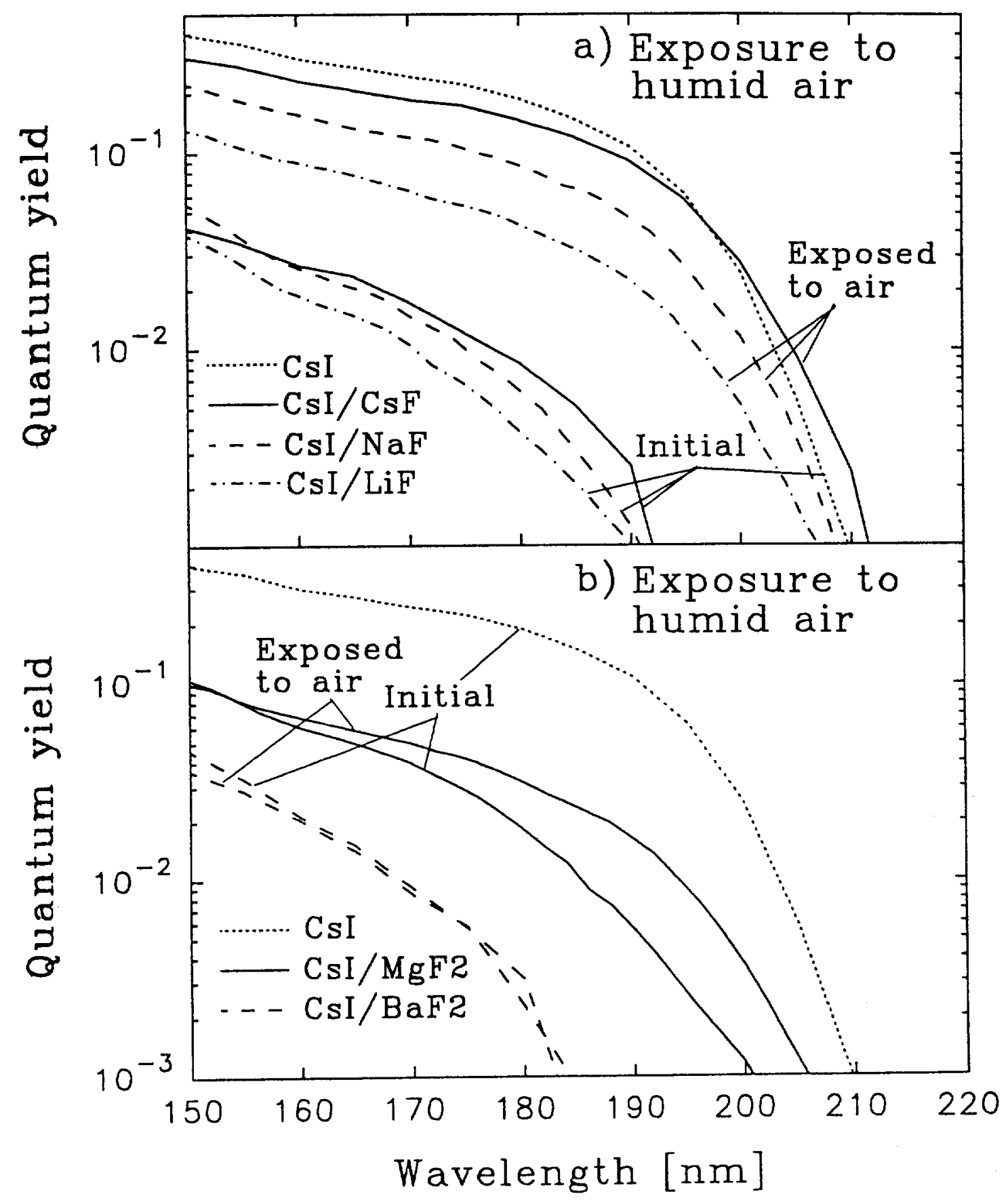

Fig.14 
